\title{
A REVIEW OF LANDSCAPE WATER REQUIREMENTS USING A MULTICOMPONENT LANDSCAPE COEFFICIENT
}

\author{
R. G. Allen, M. D. Dukes，R. L. Snyder，R. Kjelgren, A. Kilic
}

Beyond 2020,

\section{HighLIGHTS}

- A multi-component decoupling method for the landscape coefficient is described that provides a thorough means to estimate the water requirements of landscapes.

- The decoupling method considers differences in vegetation type, density, local climate, and soil water management.

- Methods for incorporating managed stress and frequency of irrigation are described.

- Winter or dormant season ET is described.

- The procedure in ASABE Standard S623 is a simpler form of the multi-component procedure and is complementary.

ABSTRACT. Water requirements of landscapes are highly variable due to the heterogeneous natures of landscapes, vegetation types, influence of buildings, and nutrient and water management. Objectives for water management of landscapes are for general appearance and health rather than for maximum biomass production. A multi-component method developed for the Irrigation Association (IA) and extended from the California WUCOLS procedure is demonstrated in which the landscape coefficient ( $K_{L}$, equivalent to a crop coefficient) is broken down into four components: vegetation type, vegetation density, microclimate, and managed stress. Each of these components can be estimated using readily made descriptions of a landscaped area and management objectives. One form of the $K_{L}$ equation is used to determine target $K_{L}$ that incorporates a target amount of soil water stress to support water conservation and to support water planning studies. A second form of the $K_{L}$ equation can be used to estimate the actual $K_{L}$ occurring under actual water management. The second form is used in studies of water balances and actual water conservation. The general decoupled equation is further expanded to optionally incorporate impacts of evaporation from exposed soil to assess impacts of irrigation frequency on total water consumption. The mathematics for the approach can be incorporated into software applications and smart irrigation controllers to produce improved water consumption estimates for landscape water requirements for use in irrigation scheduling, water requirement planning, and water depletion studies. The simplified procedure for estimating landscape water requirements in ASABE Standard S623 that is complementary to the IA procedure is discussed and compared. Both methods use a vegetation type and density system as the basis for efficiently estimating scientifically accurate landscape water requirements.

Keywords. Evapotranspiration, Irrigation requirements, Landscape coefficients, Landscape water requirements, Managed Stress, Microclimates, NAIP areal imagery.

W ater requirements and consumption by residential and urban landscapes have become increasingly important because of the quantity and value of water consumed. Procedures, which are similar to agriculture, are adapted to estimate

\footnotetext{
(c) $\$($ The authors have paid for open access for this article. This BY NG ND work is licensed under a Creative Commons Attributioncommons.org/licenses/by-nc-nd/4.0/

Submitted for review on 31 January 2020 as manuscript number NRES 13948 approved for publication as a Review Article and as part of the National Irrigation Symposium 2020 Collection by the Natural Resources \& Environmental Systems Community of ASABE on 21 July 2020.

The authors are Richard G. Allen, Professor, Kimberly Research and Extension Center, University of Idaho, Kimberly, Idaho; Michael D. Dukes, Professor, Department of Agricultural and Biological Engineering, University of Florida, Gainesville, Florida; Richard L. Snyder, Biometeorology Specialist, Division of Agriculture and Natural Resources, University of California, Davis, California; Roger Kjelgren, Director, Mid-Florida Research and Education Center, University of Florida, Apopka, Florida; Ayse Kilic, Professor, Department of Civil and Environmental Engineering and School of Natural Resources, University of Nebraska, Lincoln, Nebraska. Corresponding author: Richard G. Allen, 3793 N 3600 E, Kimberly, ID 83341; phone: 208-320-2837; e-mail: rallen@uidaho.edu.
}

evapotranspiration (ET) from landscapes. Two distinctions are made between agriculture and landscapes: (1) landscape systems often comprise mixtures of types and species of vegetation, and non-uniform spatial configurations, thereby complicating the estimation of ET, and (2) typically, the objective of landscape irrigation is to promote appearance rather than biomass production, whereas biomass production is generally maximized in agriculture.

Target ET for landscapes may incorporate intentional water stress into the baseline estimate of ET because landscape plants are often deficit irrigated to reduce water applications without substantially reducing health or appearance. Many landscape plants can often be stressed to some degree without adverse effects. This adjustment can produce considerable water conservation, and a better defined estimate for water requirements of landscapes may reduce over-irrigation of landscapes, which often occurs due to their relatively small size. Controlled stress can also reduce unneeded excessive growth, which reduces the volume of lawn and tree clippings. 
The magnitude of any managed stress in a landscape depends on the physiological and morphological requirements of the plants; the goal is to sustain health and appearance with minimal irrigation. For example, water conservation studies on turfgrass have demonstrated water savings of $20 \%$ to $30 \%$ for cool-season turfgrasses and $40 \%$ for warm-season turfgrasses without significant loss of quality (Meyer and Gibeault, 1986; Pittenger and Shaw, 2001, 2004). Some shrubs and groundcovers can be managed for even more stress-induced reduction in ET (Kjelgren et al., 2000, 2016).

A third departure of landscape ET from agricultural ET is that few landscape sites meet the "extensive surface" requirement needed to ensure equilibrium between the lower boundary layer of the atmosphere and the vegetation that is implied in the Penman-Monteith equation. Therefore, impacts of local microclimates may need to be considered in the ET estimate. The non-uniform boundary-layer equilibrium can be at the leaf level where stomates more directly regulate transpiration (Jarvis and McNaughton, 1986), such as for large specimen or street trees. Therefore, compensating adjustments are necessary to the landscape coefficient in the form of a microclimate factor to account for effects of local surroundings.

\section{TARGET ET AND ACTUAL ET}

Because of the frequent inclusion of water stress in target ET values for landscape design and management, distinction must be made between target ET values and actual ET values. Actual ET values may exceed target ET values if the landscape receives more water than required by the target that includes intentional stress. Under these conditions, landscape vegetation may exploit the additional available water, subject to some limit constrained by the environmental energy available for evaporation and the leaf area. The upper environmental energy limit, which follows behavior and principles used for agricultural crops, may exceed the target ET rate. Conversely, actual ET may be less than target ET values if stress levels to the landscape are more excessive than targeted. Therefore, two ET values for landscape are distinguished here. The first is the target landscape ET, referred to as $\mathrm{ET}_{L}$, that is based on the minimum ET levels, relative to climate, necessary to maintain a healthy, attractive landscape. The target landscape ET is useful for irrigation scheduling and water conservation planning. The second ET value is the actual landscape ET, referred to as $\mathrm{ET}_{\text {Lact }}$, that is based on landscape type and on actual water availability, which may be greater or less than the water required to establish and support target landscape $\mathrm{ET}_{L}$. The actual landscape ET is useful for water depletion studies and for hydrologic water balances. The decoupled methodology for the landscape coefficient is relatively straightforward to code into application software so that only the selection or specification of four readily described coefficients is required. Traditionally, landscape ET estimation is based on the standardized reference ET for short canopies $\left(\mathrm{ET}_{o}\right)$ rather than the reference $\mathrm{ET}$ for tall canopies $\left(\mathrm{ET}_{r}\right)$ due to the similarity between $\mathrm{ET}_{o}$ and turf grass $\mathrm{ET}$. The $\mathrm{ET}_{o}$ concept, derivation, and calculation of $\mathrm{ET}_{o}$ are presented in ASCE (2005), Allen et al. (2006), and ASCE (2016).

The target ET for a landscape is calculated as:

$$
\mathrm{ET}_{L}=K_{L} \mathrm{ET}_{o}
$$

where $\mathrm{ET}_{L}$ is the target landscape ET (in $\mathrm{mm} \mathrm{d}^{-1}, \mathrm{~mm}$ month 1 , or $\left.\mathrm{mm} \mathrm{year}^{-1}\right), \mathrm{ET}_{o}$ is the ET of a $0.12 \mathrm{~m}$ tall, cool-season grass in the same units, and $K_{L}$ is the target landscape coefficient, which is similar to the crop coefficient $\left(K_{c}\right)$ used in agricultural applications.

\section{SCOPE OF THIS STUDY}

The decoupled approach for estimating $K_{L}$ described in this study was formulated by Costello et al. (2000) in California and termed WUCOLS (water use classification of landscape species) (Costello and Jones, 1999, 2014; IA, 2003). The method was modified for use with the Landscape Irrigation Management Program (LIMP) by Snyder and Eching (2004, 2005) and Snyder et al. (2015). The decoupling method separates actual landscape ET into components for well-watered vegetation that are then adjusted with a deficit irrigation coefficient. Allen et al. (2011) and ASCE (2016) extended the decoupling procedure to enable estimation of the effects of watering frequency on landscape ET and estimation of target soil water depletion to meet water stress targets. The decoupling approach provides a relatively simple means to break $K_{L}$ into four terms that describe separate mechanisms impacting landscape ET. Each mechanism describes a factor involved in the landscape ET process that can be readily described by a user. The terms can be extracted from general, simplified tables or obtained from more rigorous, mechanical methods in the case of the managed stress coefficient and density coefficient. In addition, the procedure in ASABE Standard S623 for water requirement recommendations (ASABE, 2017), which is complementary to the IA decoupled procedure but simplified and aggregated, is discussed and compared. Both methods use a vegetation type and density system as the basis for efficiently estimating scientifically accurate landscape water requirements.

\section{BACKGROUND ON $K_{L}$ AND $K_{C}$}

The vegetation cover or crop coefficient $\left(K_{c}\right)$ that has a basis of reference crop ET $\left(\mathrm{ET}_{r e f}\right)$ was clarified by Jensen (1968) and first used in computerized irrigation scheduling by Jensen (1969) and Jensen et al. $(1970,1971)$. The procedures for estimating ET for well-watered agricultural crops that employ a $K_{c}$ and $\mathrm{ET}_{\text {ref }}$ procedure can be applied to wide range of landscape, natural, and agricultural vegetation under rainfed and irrigated conditions.

Early, refined $K_{c}$ values were developed based on daily ET values measured in lysimeters that were then related to a grass or alfalfa reference ET. Some $K_{c}$ values were refined for conditions of dry surface soil and were termed basal crop coefficients (Wright, 1982). The accuracy of ET estimates made with a dual $K_{c}$ approach, in which basal coefficients are adjusted daily according to wetness of the surface soil following rain or irrigation, is generally greater than the accuracy of ET estimates made using a single lumped $K_{c}$ value (Wright, 1982; Allen et al., 1998).

Somewhat limited experimental research exists on quantifying water needs and $K_{L}$ for the vast and diverse array of landscape plant types (Pittenger and Henry, 2005). Some of the leading work on landscape ET and $K_{L}$ for groundcovers 
and shrubs has been done in California, where water applied to landscapes in southern California is estimated to be $25 \%$ to $30 \%$ of all water used in the region (Pittenger and Shaw, 2001; Reid and Oki, 2008, 2016; Reid et al., 2018). St. Hilaire et al. (2008) produced a table of $K_{L}$ values for 35 landscape groundcovers and shrubs that were targeted to provide acceptable landscape performance after initial establishment and induce a managed amount of water stress associated with deficit irrigation strategies.

\section{LIMITATIONS ON MAGNITUDES OF LANDSCAPE COEFFICIENTS}

When applying a grass reference ET equation (ASCE, 2005, 2016) under humid conditions, in which most of the energy for the ET process is from net radiation, the maximum $K_{L}$ or $K_{c}$ for large expanses of similar vegetation does not exceed about 1.2 relative to $\mathrm{ET}_{o}$, whereas in arid or semiarid climates, where additional advection of warm dry air can occur, increasing ET from irrigated surfaces, the $K_{L}$ or $K_{c}$ can reach maximum values of about 1.3 to 1.4 relative to the grass reference (Doorenbos and Pruitt, 1977; Allen et al., 1998; ASCE, 2005). Limiting $K_{L}$ to approximately 1.3 or 1.4 for a grass reference base generally applies to large expanses of vegetation ( $>50$ to $100 \mathrm{~m}$ in the direction of wind; Allen et al., 1998).

When ET is measured from small expanses of vegetation, the internal boundary layer above the vegetation may not be in equilibrium with the underlying surface, particularly with well ventilated, tall trees (ASCE, 2016). Small expanses of tall vegetation surrounded by shorter cover can result in a "clothesline" effect in which the interchange between air and vegetation is much more efficient than over large expanses of homogeneous vegetation. In these cases, ET from isolated vegetation stands, on a per unit area basis, may be significantly greater than the corresponding $\mathrm{ET}_{o}$ computed for a grass reference, depending on stomatal behavior. Examples of this situation are ET from a single row of trees surrounded by short vegetation or even ET from a small area of grass or flowers surrounded by a dry, vegetation-free surface. Allen et al. (1992) reported $K_{c}$ values for small (6 m wide) stands of cattails and bulrushes surrounded by grass pasture equal to 1.6 to 1.8 during midseason, relative to an alfalfa reference. These measurements indicate a strong clothesline effect. An extreme illustration was provided by van Bavel et al. (1963), who measured ET from $1 \mathrm{~m}$ tall sudangrass in Arizona following cutting of the grass around a lysimeter, so that the vegetation inside the lysimeter functioned as a clothesline. After cutting, $14.7 \mathrm{~mm}$ of ET was measured during a $24 \mathrm{~h}$ period, which was a $50 \%$ increase over the $9.8 \mathrm{~mm}$ measured three days before cutting. The weather data were similar for both clear days. In a similar situation, Allen et al. (1991) measured ET from $0.6 \mathrm{~m}$ fescue grass that increased by 1.6 times relative to the PM equation when the surrounding grass was clipped to $0.1 \mathrm{~m}$, but the vegetation inside the lysimeter remained at $0.6 \mathrm{~m}$. The ET rate from the lysimeter under the clothesline condition reached $16 \mathrm{~mm} \mathrm{~d}^{-1}$, whereas the PM equation estimated $11 \mathrm{~mm} \mathrm{~d}^{-1}$ for $0.6 \mathrm{~m}$ grass having extensive fetch of other $0.6 \mathrm{~m}$ grass.

Pruitt (personal communication, 1976) reported $K_{c}$ values for a nearly isolated $4.2 \mathrm{~m}$ tall Monterey pine tree (Pinus radiata) varying from 1.4 in February-March to 2.0 during spring and summer and to 3.0 during late fall and dry earlywinter months relative to $\mathrm{ET}_{o}$. The tree grew on a $1.83 \mathrm{~m}$ by $2.44 \mathrm{~m}$ hydraulic-pillow lysimeter located within a 1 ha dry fallow field, thereby creating a clothesline effect.

The preceding discussion indicates the importance of knowing the type of setting for which ET estimates are needed. If ET estimates are to represent large expanses of similar vegetation or small stands of vegetation surrounded by mixtures of other vegetation having similar roughness and soil water conditions, then $K_{L}$ values will generally be less than or equal to 1.3 for grass references.

The ET of heterogeneous or integrated landscapes and $K_{L}$ for mixed landscapes are needed for irrigation management. In many landscapes, elevated ET from tall, narrow stands of vegetation, as described above, can reduce ET from adjacent shorter vegetation due to shading, blocking of wind and, to some extent, by cooling and humidifying the air. Therefore, development of an integrated and blended estimate for $\mathrm{ET}_{L}$ and $K_{L}$ for a landscape should be based on a composite view of the landscape that considers the mixture of vegetation types and heights, even though water requirements for tall, narrow stands of vegetation, such as trees, may be greater or less depending on stomatal behavior. Also to be considered in developing an integrated $K_{L}$ is the impact of the horizontal extent of tree roots, which tends to be larger than the canopy extent and therefore can even out water extraction over parts of a landscape and tends to integrate the $K_{L}$ of individual vegetation.

\section{DEVELOPMENT OF LANDSCAPE COEFFICIENT $\left(K_{L}\right)$}

The primary factor causing an increase in the landscape coefficient is an increase in plant cover or leaf area per unit area (LAI) as vegetation develops, resulting in a decrease in bulk surface resistance and an increase in radiative capture and aerodynamic exchange. Most publications on crop coefficients $\left(K_{c}\right)$ have presented $K_{c}$ as a time-based function of some form of absolute or scaled time basis, such as the FAOstyle example shown in figure 1. Other studies relate the rate of development of $K_{c}$ for various crops as a function of daily

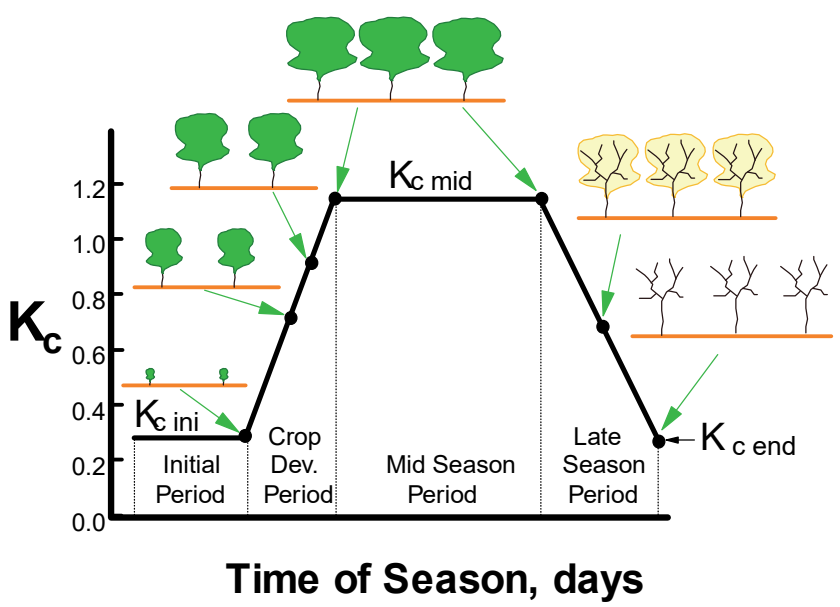

Figure 1. FAO-style crop coefficient curve and stage labeling. 
weather, such as cumulative growing degree days (Snyder, 1985; Ritchie and Nesmith, 1991; Slack et al., 1996; Snyder et al., 1999; Cesaraccio et al., 2001).

The FAO-style $K_{L}$ function shown in terms of an equivalent $K_{c}$ in figure 1 can be used to represent most landscape vegetation that has an annual cycle of low vegetation cover or vigor during winter and regrowth or return of vigor during spring. During periods of low cover or vigor, the $K_{L}$ or $K_{c}$ can be as low as 0.1 to 0.3 when averaged over the initial period in figure 1 . The $K_{L}$ reaches a maximum or near-maximum value during the mid-season period when ground cover is maximum. In the case of year-round vegetation in warm climates, the $K_{L}$ may remain at or near the midseason $K_{L}$ value. Values for $K_{L i n i}$ and $K_{L}$ end (i.e., $K_{c \text { ini }}$ and $K_{c \text { end }}$ in fig. 1) can be scaled from $K_{L \text { mid }}$ (i.e., $K_{c \text { mid }}$ in fig. 1 ) in proportion to the health and leaf condition of the vegetation at termination and the length of the late season period (i.e., whether leaves senesce slowly or are killed by frost).

\section{DECOUPLING APPROACH FOR $K_{L}$}

The above discussion describes the potentially wide range of values for $K_{L}$ that can be caused by the surrounding vegetation and/or dryness of the surrounding environment. $K_{L}$ can also have a broad range of values due to variation in the vegetation density. As a result, Costello et al. (2000) developed the WUCOLS procedure, in which $K_{L}$ was decoupled into reproducible and visually apparent components representing the effects of four factors that determine the value for $K_{L}$. The decoupling was done to facilitate application to the wide diversity of vegetation types and environments of landscape systems. Snyder and Eching (2004, 2005) and Snyder et al. (2015) proposed a similar decoupling procedure for estimating a formulated $K_{L}$ that uses ranges for the $K_{L}$ components different from those of Costello et al. (2000) and in which the ranges for the $K_{d}$ and $K_{s m}$ factors are normalized to limit their ranges to 0 to 1.0. Snyder and Eching (2004) and Snyder et al. (2015) modified the WUCOLS procedure in the Landscape Irrigation Management Program (LIMP) to the following form:

$$
K_{L}=K_{v} K_{d} K_{s m} K_{m c}
$$

where $K_{v}$ is the vegetation species factor (0.7 to 1.2$), K_{d}$ is the vegetation density factor ( 0 to 1.0$), K_{m c}$ is the microclimate factor ( 0.5 to 1.5$)$, and $K_{s m}$ is the managed stress factor (0 to 1.0). $K_{v}$ is the ratio of $\mathrm{ET}_{v}$ to $\mathrm{ET}_{o}$ for a specific single or mixture of plant species under full soil water supply, where $\mathrm{ET}_{v}$ is the vegetation ET assuming no water deficit and essentially full ground cover, defined by Snyder and Eching (2004) and Snyder et al. (2015) as having more than $70 \%$ to $80 \%$ of the ground covered or shaded by vegetation. Therefore, $K_{v}$ represents the maximum $K_{L}$ expected for vegetation or for a mixture of vegetation under no soil water stress and where no microclimate adjustments are required. Factors $K_{d}, K_{s m}$, and $K_{m c}$ modify $K_{v}$ for less than effective full ground cover $\left(K_{d}\right)$, for intentional water stress $\left(K_{s m}\right)$, and for micro-climate differences due to shading, light reflection from structures, fetch and wind exposure, and slope and aspect impacts on radiation $\left(K_{m c}\right)$. Each of these factors can be estimated separately from the others based on visual observation of the landscape (for $K_{d}$ and $K_{m c}$ ) and based on user experience for $K_{s m}$ (Reid and Oki, 2008, 2016; Reid et al., 2018).

Following the estimation of the individual factors, $K_{L}$ is calculated using equation 2 to produce a landscape-specific estimate of relative landscape ET. The landscape-specific $K_{L}$ can improve water conservation efforts by better matching irrigation additions to landscape-specific conditions, including a targeted soil water stress level. The form of the $K_{L}$ equation in equation 2 is used to determine the target $K_{L}$, which may include a targeted amount of soil water stress to support water conservation and to support water planning studies. A second form of the $K_{L}$ equation, provided later as equation 17, can be used to estimate the actual $K_{L}$ occurring under actual water management. The second form is used in studies of water balances and actual water conservation where the actual ET from the landscape is needed.

An alternative form of equation 2 from the Irrigation Association (IA, 2011) adds the variable effects of evaporation from the soil between vegetation, which may be significant during frequent wetting by rainfall or irrigation, and is patterned after the dual $K_{c}$ procedure of FAO-56 (Allen et al., 1998):

$$
K_{L}=\left[\left(1-K_{d}\right) K_{\text {soil }}+K_{v} K_{d} K_{s m}\right] K_{m c}
$$

where $K_{\text {soil }}$ is the evaporation coefficient representing evaporation from the soil surface (relative to $\mathrm{ET}_{o}$ ) caused by wetting by precipitation or irrigation. $K_{\text {soil }}$ is included in equation 3 to consider the impact of evaporation occurring between plants. In the context of equation 3 , the $K_{v}$ coefficient represents the potential transpiration from the vegetation component when the soil surface is infrequently wetted and mostly dry, so that evaporation from soil is treated separately by $K_{\text {soil }}$. The impact of $K_{\text {soil }}$ is strongest when plant density $\left(K_{d}\right)$ is low and the frequency of soil wetting is high. $K_{\text {soil }}$ is less impactful with greater plant density or greater $K_{v} . K_{\text {soil }}$ is estimated as a function of soil wetting frequency and magnitude of $\mathrm{ET}_{o}$ from figure 2 (originating from figure 29 of FAO-56; Allen et al., 1998). $K_{\text {soil }}$ can also be estimated using equations from ASCE (2016) and Allen et al. (1998, 2005), where $K_{\text {soil }}$ is referred to as $K_{e}$ or $K_{\text {ini }}$ for bare soil conditions.

Equation 3 reverts to equation 2 when $K_{\text {soil }}=0$. However, in that case, $K_{v}$ should include the impacts of evaporation from the soil. Equation 3 is useful to assess the impact of irrigation frequency on total ET of a landscape having less than full ground cover. Effects of evaporation of water intercepted by vegetation following irrigation or precipitation are estimated with equations 20 to 22 described later. Equation 3 provides estimates for $K_{L}$ over an extended period of time in which the effects of evaporation from the soil, over time, are averaged through the estimate of $K_{\text {soil }}$. More refined estimates, when needed, can be made using a daily water balance for the surface soil layer using the dual $K_{c b}+K_{\text {soil }}$ procedure described by Allen et al. $(1998,2005)$ and ASCE (2016), in which the basal crop coefficient $\left(K_{c b}\right)$ of the FAO procedure is set equal to a $K_{v}$ value that represents a relatively dry soil surface, and $K_{\text {soil }}$ is estimated daily in accordance with the wetting frequency. Refined daily estimates 

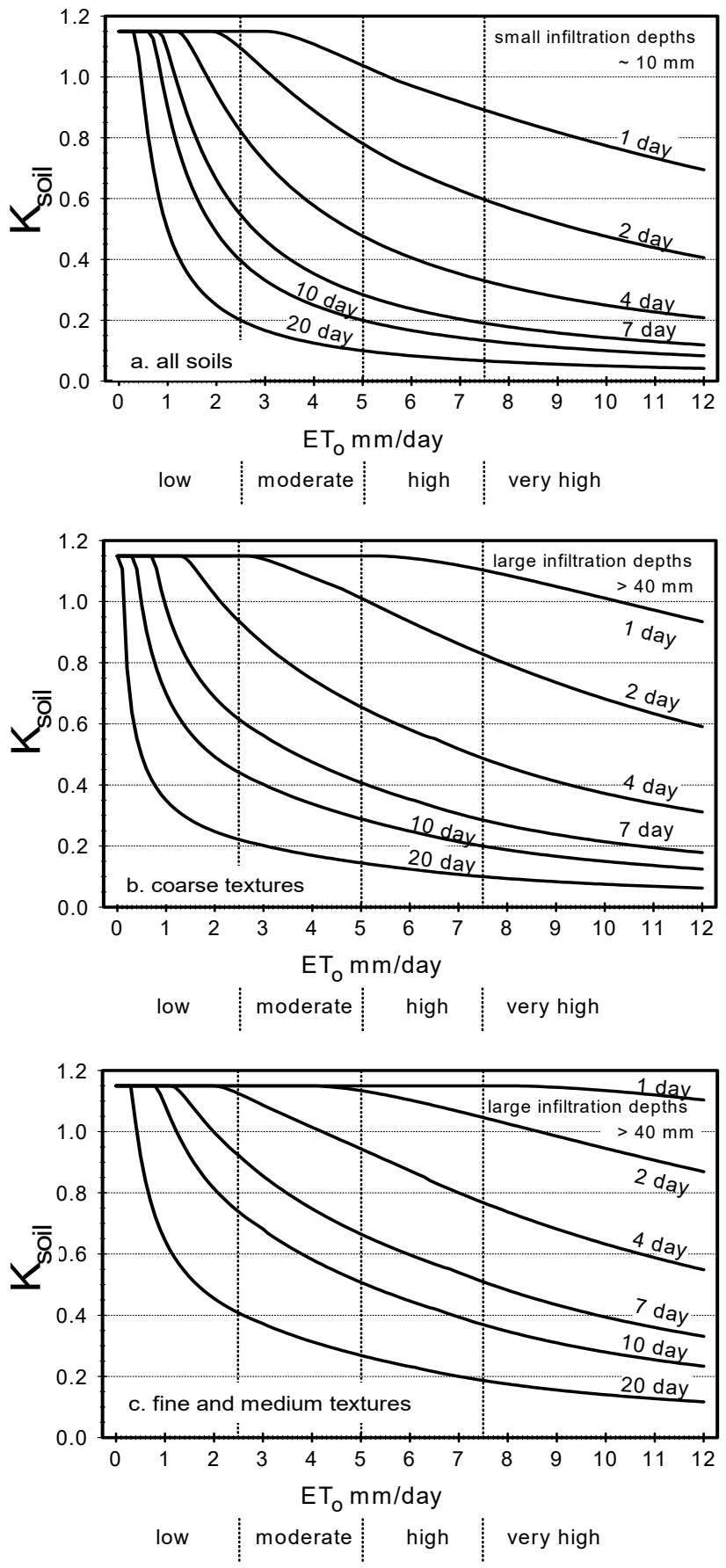

Figure 2. Average $\boldsymbol{K}_{\text {son }}$ for a bare soil surface as related to the level of grass reference $\mathbf{E T}_{o}$ and the interval between irrigations or significant rainfall: (a) all soil types when wetting events are about $10 \mathrm{~mm}$ per event, (b) coarse-textured soils when wetting events are greater than about $40 \mathrm{~mm}$, and (c) medium and fine-textured soils when wetting events are greater than about $40 \mathrm{~mm}$ (after FAO-56; Allen et al., 1998).

might be desirable during computer modeling for specific landscapes where the daily water balance and associated equations can be scripted into software code and the specific wetting frequency is known or can be estimated. Ordinarily, equation 3 will provide satisfactory and sufficient estimates for $K_{L}$ for purposes of irrigation scheduling, estimation of water conservation impacts, and for general water depletion studies.
Reference ETo as Influenced by Microclimate

Reference $\mathrm{ET}_{o}$, which represents weather-based effects on potential ET, is influenced by the microclimate of a landscape. A local environment that is surrounded by dry areas or by buildings and walkways is often subjected to more longwave radiation and local advection of sensible heat, compared to areas surrounded by vegetation, due to the surrounding elevated surface temperatures. This can cause the potential demand for the area to exceed that for the standardized $\mathrm{ET}_{o}$, which represents the near-maximum ET from an extensive surface of short grass. An altered reference $\mathrm{ET}_{o}$, termed $\mathrm{ET}_{o} m c$, is defined as the $\mathrm{ET}_{o}$ within the microclimate where the vegetation grows. The local $\mathrm{ET}_{\text {o } m c}$ can deviate from the regional $\mathrm{ET}_{o}$, which represents a regional estimate of reference ET based on measured weather data from an open, vegetated area. Thus, $\mathrm{ET}_{o m c}$ is a local $\mathrm{ET}_{o}$ corrected for microclimate differences. The microclimate coefficient, $K_{m c}=\mathrm{ET}_{o m c} / \mathrm{ET}_{o}$, is estimated or determined experimentally and is described in a later section.

\section{Vegetation Coefficient}

The $K_{v}$ for landscape vegetation represents the ratio of $\mathrm{ET}_{v}$ to $\mathrm{ET}_{o m c}$ that occurs when generally $70 \%$ or more coverage (shading) of the ground exists and the soil water supply is full. $\mathrm{ET}_{o m c}$ is used as the basis for $K_{v}$ because $\mathrm{ET}_{v}$ represents the ET for the vegetation in the same microclimate as represented by $\mathrm{ET}_{o m c} . K_{v}$ is expected to have a relatively constant value over ranges of microclimate because $\mathrm{ET}_{v}$ and $\mathrm{ET}_{o m c}$ are both impacted by the same microclimatic factors. As a result, $K_{v}$ defines the maximum ratio $K_{L}=\mathrm{ET}_{v} / \mathrm{ET}_{o}$ m for vegetation under non-deficit irrigation conditions. In other words, $K_{v}$ is the fraction of $\mathrm{ET}_{o m c}$ when the foliage has $K_{d}=1.00$ and full water availability $\left(K_{s m}=1.00\right)$. Many types of landscape vegetation tend to exhibit similar values for $K_{v}$ due to similarities in total leaf area, stomatal response, and energy absorption. Therefore, condensed tables of typical values for general species types are employed to provide general estimates for $K_{v}$, where $K_{v}$ typically ranges from 0.8 to 1.2 (IA, 2011). Because landscape vegetation is commonly taller and rougher than turf grass, the upper limit for $K_{v}$ can exceed 1.00 for well-watered landscapes. Table 1 contains general values for $K_{v}$ for general types of landscape vegetation. Primary sources for the values in table 1 are listed in the table footnotes.

The typical $K_{v}$ values in table 1 represent full effective ground cover when the fraction of the surface covered by vegetation $\left(f_{c}\right)$ is greater than about 0.70 and for no water deficit conditions. The $K_{v}$ values in table 1 are general, assume that $K_{d}=1.00$, and assume no ET-reducing water stress, so $K_{s m}=1.00$. The $K_{v}$ values apply for the full range of microclimate factor $K_{m c}$. The soil factor $\left(K_{s m}\right)$ is less than 1.00 when the landscape is deficit irrigated (Brown et al., 2001; Jia et al., 2009). The $K_{v}$ value for trees applies most readily to species adapted to abundant soil water, such as Populus spp. and other riparian species, while many other tree species may fall closer to the $K_{v}$ of shrubs. More information is given by Kjelgren et al. (2016) and in the WUCOLS literature cited earlier.

The $K_{v}$ values for both cool-season (CS) and warm-season (WS) grasses are less than 1.00 in table 1 due to the 
Table 1. General vegetation factors $\left(K_{V}\right)$ for general plant types for high-density coverage (shading) of the ground and full water supply (IA, 2011; ASCE, 2016).

\begin{tabular}{|c|c|c|}
\hline & Vegetation Category $^{[\mathrm{a}]}$ & $K_{v}$ \\
\hline & Trees & 1.15 \\
\hline & Shrubs, des & 0.70 \\
\hline & Shrubs, non-d & 0.80 \\
\hline & Groundcover & 1.00 \\
\hline & Annuals & 0.90 \\
\hline & Mixture of trees, shrubs, and groundcover ${ }^{[b]}$ & 1.20 \\
\hline & Cool-season turfgrass ${ }^{[\mathrm{c}]}$ & 0.90 \\
\hline & Warm-season turfgrass ${ }^{[\mathrm{d}]}$ & 0.90 \\
\hline & \multicolumn{2}{|c|}{$\begin{array}{l}\text { The tree, shrub, and groundcover categories are for landscapes com- } \\
\text { posed solely or predominantly of one of these vegetation types with } \\
\text { somewhat dense coverage (shading) of the ground. Primary data } \\
\text { sources include Aronson et al. (1987) and Brown et al. (2001) for cool- } \\
\text { season turfgrass, Brown et al. (2001) and Jia et al. (2009) for warm- } \\
\text { season turfgrass, and IA (2011) for other vegetation. }\end{array}$} \\
\hline [b] & \multicolumn{2}{|c|}{$\begin{array}{l}\text { Mixed plantings are composed of two or three vegetation types where } \\
\text { a single vegetation type does not dominate. }\end{array}$} \\
\hline [c] & \multicolumn{2}{|c|}{$\begin{array}{l}\text { Cool-season grasses include Kentucky bluegrass, fescues, and peren- } \\
\text { nial ryegrass. }\end{array}$} \\
\hline [d] & \multicolumn{2}{|c|}{$\begin{array}{l}\text { Warm-season grasses include bermuda grass, St. Augustine grass, buf- } \\
\text { falo grass, and blue grama. The } K_{v} \text { value for warm-season turfgrass is a } \\
\text { maximum expected value under full water supply. In practice, the } K_{L} \\
\text { for grass is lowered by inducing some degree of stress so that } K_{s m} \text { in } \\
\text { equations } 2 \text { and } 3 \text { is less than } 1 \text {, for example } K_{s m}=0.7 \text {. }\end{array}$} \\
\hline
\end{tabular}

tendency of their mean height to be less than that of the standardized $0.12 \mathrm{~m}$ clipped grass reference. Differences in water use rates have been noted between cultivars of CS and WS grasses (Harivandi et al., 2009), so that the values in table 1 represent averages for typical cultivars. The $K_{v}$ value for WS grass in table 1 is equal to that for CS grass because both of these grass types tend to have similar $\mathrm{ET}_{v} / \mathrm{ET}_{o m c}$ under conditions of no water stress (Brown et al., 2001; Smeal et al., 2005). Warm-season grasses use $\mathrm{C} 4$ photosynthesis mechanisms, as compared to $\mathrm{C} 3$ mechanisms for cool-season grasses (Qi and Redmann, 1993; Way et al., 2014). As a result, WS grasses tend to have more effective stomatal control and survive water stress better than CS grasses due to their physiology and superior drought avoidance and drought resistance mechanisms (Harivandi et al., 2009; Way et al., 2014). As a consequence, it is not necessary to irrigate WS grasses as much as CS grasses. Warm-season grasses are also more heat tolerant, so they can warm more than CS grasses without adverse effects on photosynthesis or growth. However, if WS and CS grasses are irrigated frequently, ET rates between CS and WS grasses will be comparable, but frequent irrigation is not necessarily a good practice.

Users are encouraged to manage irrigation of WS grasses where a managed stress factor of about 0.7 is targeted (Harivandi et al., 2009) so that, given $K_{d}=1.00$ and $K_{m c}=1.00$, the $K_{L}$ in equation 2 is $0.90(1.00)(0.70)(1.00)=0.63$. In other words, some level of stress can be applied to WS grasses with little visual effect, as is illustrated later in table 3 . The $\mathrm{Kv}$ value for WS grass is listed as 0.90 in table 1 to provide the best accuracy when calculating ETL in water balances for hydrology and water conservation studies, where Ksm may have a value of 1.00 during times of frequent rainfall, and therefore a WS grass may transpire similarly to a CS grass during well-watered periods. Comparison of KL for WS grasses from equation 2 and tables 1 to 3 with measurements in a Florida application are presented in figure 4, which shows $K_{L}$ for WS grass close to 0.60 during summer when water stress occurs. There is an increase in September due to rainfall.

The $K_{v}$ values for groundcover and annuals or flowers are assumed equal to 0.9 to 1.0 , reflecting the likely $K_{v}$ when vegetation completely covers the ground and when no ETreducing stress occurs. Because of the hundreds, if not thousands, of species of flowers and groundcover types, estimating or establishing $K_{v}$ values for each species is not feasible. Instead, a general expected upper limit for $K_{v}$ is established, and lower values are possible if specific information for a species is available.

Carrow (2004) suggested that common target values for $K_{L}$ for cool-season grasses range from 0.70 to 0.95 in the southeast U.S., as compared with $K_{L}$ for warm-season turfgrasses of 0.65 to 0.85 when the irrigation regime is 3 to $7+$ days between events, which allows mild water stress during hot periods. Costello et al. (2000) and Harivandi et al. (2009) recommended 0.80 and 0.60 for CS and WS grasses in California, where there is less rainfall and less dew deposition than in the southeast U.S. At these $K_{L}$ values, turf generally maintains acceptable quality and growth. As $K_{L}$ values fall below these general ranges using a similar irrigation schedule but with smaller doses per irrigation, turf performance and appearance may rapidly decline. Carrow (1995) reported turfgrass $\mathrm{ET}_{L}$ to be $40 \%$ to $60 \%$ less in a humid environment compared with the same cultivar in an arid environment, but with similar $K_{L}$ values for both environments. This is primarily due to differences in $\mathrm{ET}_{o}$. The data from Carrow $(1995,1996)$ apply to $K_{L}$ estimated with equations 2 and 3, rather than to values for the $K_{v}$ factor in table 1, which represent starting points in the $K_{L}$ estimation process.

\section{Density Factor}

Landscapes can vary considerably in terms of vegetation density, with potential for variation in plant spacing, size, and maturity. Vegetation density is impacted by the collective leaf area of all plants in the unit landscape area and the structure of the leaf area. More densely growing vegetation with a larger fraction of ground shaded by vegetation will have a greater $K_{d}$ and will transpire and require more water. Immature and sparsely planted landscapes tend to have less total leaf area per unit landscape area than mature landscapes and have a lower value for $K_{d}$. Often, landscapes have two and three tiers (horizontal levels) of vegetation, including turf or groundcover, shrubs, and trees. Overlapping tiers are capable of more radiative absorption and other energy exchange and tend to increase ET, as shown by the $K_{v}$ value of 1.20 in table 1 for the "mixture" category. The important factor is the fraction of the sunlight intercepted by plants and by the ground. By observations at different times of the day, the fraction of direct sunlight reaching the ground can be estimated, which represents $1-f_{c \text { eff, }}$, where $f_{\text {c eff }}$ is the effective fraction of ground shaded by vegetation and is impacted by plant height and sun angle. The plant light interception is usually slightly more than the percentage of ground cover due to sun angle effects, so that the observed light interception can be used to estimate the $K_{d}$ factor. If more than $80 \%$ of the sunlight on the landscape is intercepted by the plants over the day, then the $K_{d}$ factor should be close to 1.00 (Snyder et al., 1999, 2015; Kjelgren et al., 2016). 
Initial estimates of the plant density factor $\left(K_{d}\right)$ can be made using a direct relationship between $K_{d}$ and the effective fraction of ground covered by vegetation $\left(f_{c e f f}\right)$, with some adjustment for vegetation height. The $f_{c \text { eff }}$ value and the approximated $K_{d}$ both range from 0 to 1.00 . An estimate for $K_{d}$ that considers the effects of vegetation height and shading uses a relationship provided by Allen and Pereira (2009):

$$
K_{d}=\min \left[1, M_{L} f_{c e f f}, f_{c e f f}^{\left(\frac{1}{1+h}\right)}\right]
$$

where $f_{c \text { eff }}$ is the effective fraction of ground covered or shaded by vegetation near solar noon ( 0.01 to 1.00$), M_{L}$ is a multiplier of $f_{c \text { eff }}$ describing the effect of canopy density, root density, and stomatal conductance on maximum sustainable relative ET per fraction of ground shaded (1.50 to 2.00), and $h$ is the mean height of the vegetation (m). Equation 4 suggests that, as $h$ increases, the total leaf area and resulting net radiation will increase for the same level of $f_{c \text { eff }}$, thereby increasing $K_{d}$ and consequently $K_{L}$. In addition, as $h$ increases, there is more daily light interception and more opportunity for micro-advection of heat from soil to canopy, which increases turbulent exchange within the canopy for the same amount of ground coverage. Both increasing net radiation and turbulent exchange will increase the relative magnitude of $K_{L}$ via the $K_{d}$ factor. The $f_{c \text { eff }}$ and $h$ values are relatively easy to estimate. When two substantial tiers of vegetation are present, e.g., trees shading grass or flowers, the $h$ value can be approximated in proportion to the $f_{\text {c eff }}$ value for each tier (Snyder and Eching, 2004, 2005; Costello et al., 2000). Equation 4 is congruent with the Snyder-Eching (2005) definition of $K_{d}$, in which $K_{d}$ ranges from 0.00 to 1.00 .

For canopies such as trees or randomly planted vegetation, $f_{c \text { eff }}$ can be estimated from Allen et al. (1998) as:

$$
f_{c \text { eff }}=\frac{f_{c}}{\sin (\beta)} \leq 1
$$

where $f_{c}$ is the fraction of ground shaded by vegetation from a view directly overhead of the vegetation, and $\beta$ is the mean angle of the sun above the horizon during the period of maximum ET (generally between 11:00 and 15:00 h). Generally, $f_{c \text { eff }}$ can be assigned to solar noon $(12: 00 \mathrm{~h})$, so that $\beta$ can be calculated as:

$$
\beta=\arcsin [\sin (\phi) \sin (\delta)+\cos (\phi) \cos (\delta)]
$$

where $\phi$ is latitude, and $\delta$ is solar declination defined in standard texts (Allen et al., 1998; ASCE, 2005, 2016).

The $M_{L}$ multiplier of $f_{c \text { eff }}$ in equation 4 imposes an upper limit on the relative sustainable magnitude of transpiration per unit of ground area, as represented by $f_{c \text { eff }}$ (Allen et al., 1998), and is expected to range from 1.5 to 2.0, depending on the canopy density, thickness, and maximum conductance. Parameter $M_{L}$ is an attempt to simulate the physical limits imposed on water flux by the plant root, stem, and leaf systems (Allen and Pereira, 2009). The value for $M_{L}$ can be modified to fit specific vegetation. Figure 3 shows values for $K_{d}$ by equation 4 over a range of $f_{c \text { eff }}$ and $h$ values for $M_{L}=$

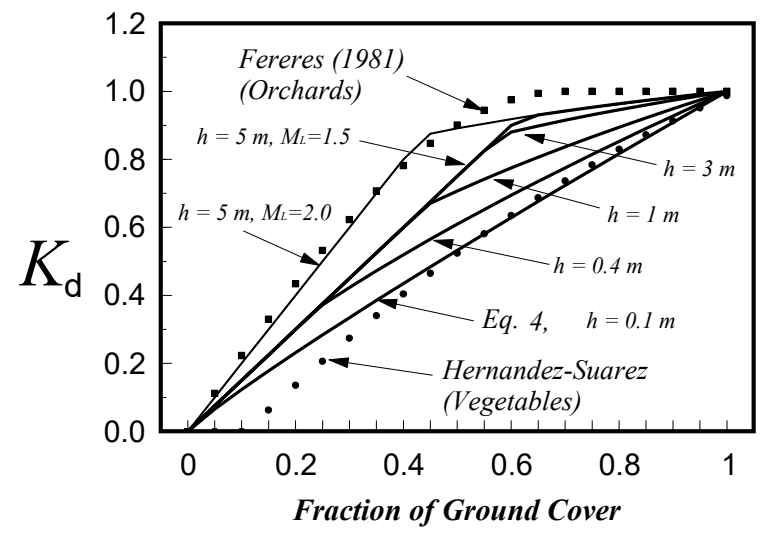

Figure 3. Density coefficient $\left(K_{d}\right)$ estimated from equation 4 with $M_{L}=$ 1.5 over a range of ground cover fractions and various plant heights and compared with estimates by Fereres (1981) for orchards and by Hernandez-Suarez (1988) for vegetables (comparative data from Fereres, 1981, and Hernandez-Suarez, 1988).

1.5 and for $M_{L}=2$ when $h=5 \mathrm{~m}$. The estimates agree with those previously suggested by Fereres (1981) for orchards and by Hernandez-Suarez (1988) for vegetables, which represent two near extremes of typical plant height.

When the mean stomatal control by landscape vegetation (i.e., stomatal resistance, $r_{1}$ ), particularly for freestanding and taller trees, is greater than that for agricultural vegetation, which is often bred to maximize stomatal opening and biomass production, then FAO-56 (Allen et al., 1998) suggests that the estimate by equation 4 be reduced by about $10 \%$ or $20 \%$ for each doubling of $r_{1}$ above $100 \mathrm{~s} \mathrm{~m}^{-1}$.

\section{Microclimate Factor}

The microclimate factor $\left(K_{m c}\right)$ accounts for impacts on ET by sun, external shading, protected areas, hot and cool areas, reflected and emitted radiation from structures, wind, and transfer of heat energy from low-ET surroundings. Structures and paved areas, which are typical of urban landscapes, can have pronounced effects on the local energy balance due the transfer of energy for evaporation from these surfaces to local vegetation. The environmental conditions of a landscape can vary significantly across a landscape, for example, areas on the south side of a building versus areas on the north side. Plantings adjacent to paved, open areas may have 50\% greater ET demand (Costello et al., 2000) than similar plantings bordered by other vegetation due to the transfer of energy to the vegetation from the nonevaporating areas. However, for woody plants, this response depends on ventilation and stomatal behavior (Kjelgren and Montague, 1998). Conversely, plantings in areas shaded from sun and shielded from wind may have ET rates that are only one-half as high as those in open areas (Costello et al., 2000; Snyder et al., 2015). An important factor is wind shielding by buildings and vegetation. Reference ET weather stations are typically placed in well-exposed areas to measure wind speeds that represent the region. If the landscape is exposed to less wind due to shielding by buildings or vegetation, then the $\mathrm{ET}_{o m c}$ (see earlier definition) may be less than $\mathrm{ET}_{o}$. The LIMP program from Snyder and Eching $(2004,2005)$ and Snyder et al. (2015) provides a methodology to address these microclimate factors. 
Table 2. Microclimate factor $\left(K_{m c}\right)$ for landscape plant types (after IA, 2003, 2011; Costello et al., 2000; ASCE, 2016).

\begin{tabular}{cccc}
\hline & $\begin{array}{c}\text { High } \\
\text { (Harsh } \\
\text { Environment) }\end{array}$ & $\begin{array}{c}\text { Average } \\
\text { (Reference } \\
\text { Condition) }\end{array}$ & $\begin{array}{c}\text { Low } \\
\text { (Protected } \\
\text { Environment) }\end{array}$ \\
\hline Trees & 1.4 & 1.0 & 0.5 \\
Shrubs & 1.3 & 1.0 & 0.5 \\
$\begin{array}{c}\text { Groundcover, flowers } \\
\text { Mixture of trees, shrubs, } \\
\text { and groundcover }\end{array}$ & 1.2 & 1.0 & 0.5 \\
$\quad 1.4$ & 1.0 & 0.5 \\
Turfgrass & 1.2 & 1.0 & 0.8 \\
\hline
\end{tabular}

Values for $K_{m c}$ are listed in table 2 for general classes of vegetation. The high category $\left(K_{m c}>1\right)$ reflects harsh microclimate conditions such as planting in direct sunlight near paved or other non-vegetated surfaces, near reflective or heat-emitting surfaces such as windows or buildings, or in exposed, windy conditions. The low category $\left(K_{m c}<1.00\right)$ represents environments where the plantings are shaded, shielded from wind, and away from dry, hot surfaces. The average or medium category $\left(K_{m c}=1.00\right)$ represents reference conditions that are similar to open settings, such as parks, where conditions caused by buildings, pavement, shade, and reflection do not influence the ET by the landscape. The values given for $K_{m c}$ are approximate, and local measurements can be used to confirm these values or derive local values. Values for $K_{m c}$ can be interpolated between the high, average, and low categories and should be selected for each sector of a landscape.

\section{Managed Stress Factor}

Typically, the objective of landscape irrigation is to promote appearance rather than biomass production, unlike agriculture where biomass is generally maximized. Therefore, the target ET for landscapes can include an intentional and managed stress factor in the baseline value for $\mathrm{ET}_{L}$, where landscape plants are watered less than they would be if they were irrigated like an agricultural crop. This management is done by adjusting the irrigation schedule to apply less water than the vegetation will potentially transpire. The magnitude of the stress factor depends on the physiological requirements and morphological characteristics of the plants and the desired or minimum acceptable appearance.

The managed stress factor $\left(K_{s m}\right)$ represents the fraction of the full ET rate targeted to obtain the functional and visual characteristics of the landscape vegetation. Parameter $K_{s m}$ has a range of 0.00 to 1.00 , where 1.00 represents conditions of no water stress and 0.00 represents no plant transpiration and probable plant dormancy or death. High $K_{s m}$ values will sustain predominately lush, high leaf area vegetation stands that tend to maximize ET. Low $K_{s m}$ values represent substantial managed plant water stress and reduction in ET, generally at the cost of biomass accumulation and potentially loss of pleasant visual effects (Richie and Pittenger, 2000; Harivandi et al., 2009). Typical approximate values for $K_{s m}$ are presented in table 3 . These values, when inserted into equation 2 with values for $K_{v}$ from table 1, produce values for $K_{L}$ that are similar to those reported by Meyer and Gibeault (1986), Smeal et al. (2001), Carrow (2004), and Pittenger and Shaw (2007).

Many landscape species exercise significant stomatal control over transpiration and can be forced toward lower
Table 3. Managed stress factor $\left(K_{s m}\right)$ for landscape plant types and soil water depletion fraction $(p)$ for no transpiration-reducing stress. ${ }^{[a]}$

\begin{tabular}{|c|c|c|c|c|}
\hline Vegetation Category & $\begin{array}{l}\text { High } \\
\text { Stress }\end{array}$ & $\begin{array}{c}\text { Average } \\
\text { Managed } \\
\text { Stress }\end{array}$ & $\begin{array}{l}\text { Low } \\
\text { Stress }\end{array}$ & $\begin{array}{c}\text { Depletion } \\
\text { Fraction } \\
(p)\end{array}$ \\
\hline Trees & 0.4 & 0.6 & 0.8 & 0.6 \\
\hline Shrubs, desert species & 0.3 & 0.4 & 0.6 & 0.6 \\
\hline Shrubs, non-desert species & 0.4 & 0.6 & 0.8 & 0.6 \\
\hline Groundcover & 0.3 & 0.5 & 0.8 & 0.5 \\
\hline Annuals (flowers) & 0.5 & 0.7 & 0.8 & 0.4 \\
\hline $\begin{array}{l}\text { Mixture of trees, shrubs, } \\
\text { and groundcover }\end{array}$ & 0.4 & 0.6 & 0.8 & 0.6 \\
\hline Cool-season turfgrass & 0.7 & 0.8 & 0.9 & 0.4 \\
\hline Warm-season turfgrass & 0.6 & 0.7 & 0.8 & 0.5 \\
\hline
\end{tabular}

[a] Data are from the Irrigation Association (IA, 2011).

[b] Mixed plantings are composed of two or three vegetation types where a single vegetation type does not predominate.

levels of ET (Jarvis and McNaughton, 1986). For instance, the low $K_{s m}$ for groundcover is 0.3 , which may be appropriate for a select group of drought-tolerant groundcover species. This value may not be appropriate for some ornamental groundcovers that require more water (and less water stress) to maintain health and appearance. In addition, dry air (high vapor pressure deficit) can impose evaporative stress on many woody species, resulting in stomatal closure (Choudhury and Monteith, 1986). Local or regional sources can help with determining appropriate values for $K_{s m}$. Pittenger and Shaw (2007) suggest $K_{L}$ for more than 30 groundcovers and shrubs grown in southern California that contain low $K_{s m}$ components and thus provide good water conservation. Many of the vegetation types listed by Pittenger and Shaw (2007) are native desert plants that tolerate water stress. Other sources of target $K_{L}$ information for specific species that include recommended $K_{s m}$ include the WUCOLS publications by Costello and Jones (1999) and Costello et al. (2000) and ASABE Standard S623 (ASABE, 2017), where $K_{L}$ includes an implied $K_{s m}<1.0$. Costello and Jones (2014) and https://ucanr.edu/sites/UCLPIT/ provide categorized $K_{L}$ levels (low, medium, and high) for a large variety of landscape vegetation, where $K_{L}$ includes an implied $K_{s m}$.

Management of landscape vegetation to implement a particular $K_{s m}$ requires selection of a target depletion fraction prior to irrigation that produces the $K_{s m}$, on average. Typically, trees, shrubs, and groundcover managed for the highstress category are not irrigated and rely on rainfall. In situations where irrigation is practiced, the irrigation interval must be sufficiently long to produce increasingly greater stress as soil water is depleted between irrigations so that the stress factor, averaged over the entire interval, equals the desired value for $K_{s m}$.

\section{Computational Derivation of $\boldsymbol{K}_{\text {sm }}$}

Refined estimates for the $K_{s m}$ parameter in equations 2 and 3 can be derived by employing a daily water balance of the rooting zone of vegetation in which a daily stress coefficient $\left(K_{s}\right)$ is defined as the ratio of actual ET to potential ET $\left(\mathrm{ET}_{p o t}\right)$ for the vegetation, so that $\mathrm{ET}_{a c t}=K_{s} \mathrm{ET}_{p o t}$, where ETpot represents the maximum ET expected for the landscape vegetation under non-water limiting conditions. When $K_{s m}=$ $1.0, \mathrm{ET}_{p o t}=K_{L} \mathrm{ET}_{o}$ from equations 2 and 3 . The refined estimates for $K_{s m}$ are recommended for computer modeling of 
irrigation water management to meet target $K_{L}$ and for developing recommended water schedules specific to individual landscapes.

A simple linear model for estimating $K_{s m}$, described in FAO-33 (Doorenbos and Kassam, 1979), is commonly used:

$$
K_{s m}=\frac{\theta-\theta_{w p}}{\theta_{t}-\theta_{w p}} \text { for } \theta<\theta_{t}
$$

where $\theta$ is mean volumetric soil water in the root zone $\left(\mathrm{m}^{3}\right.$ $\mathrm{m}^{-3}$ ), and $\theta_{t}$ is the threshold $\theta$ below which transpiration is decreased linearly due to water stress. $K_{s m}=1.00$ for $\theta \geq \theta_{t}$. The wilting point $\left(\theta_{w p}\right)$ is the soil water at the lower limit of soil water extraction by plant roots $\left(\mathrm{m}^{3} \mathrm{~m}^{-3}\right)$. The $\theta_{t}$ is estimated from the relationship:

$$
\theta_{t}=(1-p)\left(\theta_{f c}-\theta_{w p}\right)+\theta_{w p}
$$

where $p$ is the average fraction of available soil water that can be depleted before water stress and ET reduction occur. Variable $p$ is similar to the management-allowed depletion (MAD) used by some approaches, although the value set for MAD can involve some water stress, if that is a desired outcome. MAD can also consider other factors such as salinity (Hunsaker et al., 2011). Variable $\theta_{f c}$ is the soil water content at field capacity or the drained limit of the soil in $\mathrm{m}^{3} \mathrm{~m}^{-3}$. Values for all $\theta$ parameters should represent averages over the effective root zone. Typical values of $\theta_{w p}$ and $\theta_{f c}$ are listed in standard texts such as Doorenbos and Pruitt (1977), Allen et al. (1998), and ASCE (2016) for various soil texture classes.

The parameter $p$ normally ranges from 0.30 depletion of available soil water $\left(\theta_{f c}-\theta_{w p}\right)$ for shallow-rooted plants or plants having low root density at high rates of $\mathrm{ET}_{c}(>8 \mathrm{~mm}$ $\mathrm{d}^{-1}$ ) to 0.70 for deep-rooted plants having high root density at low rates of $\mathrm{ET}_{c}\left(<3 \mathrm{~mm} \mathrm{~d}^{-1}\right)$ (Appendix B in Raes et al., 2009). A value of 0.50 is commonly used for $p$ for many agricultural crops.

An expression equivalent to equation 7 for daily calculation but in terms of depletion $\left(D_{r}\right)$ of available water in the root zone is:

$$
\begin{gathered}
K_{s m}=\frac{\mathrm{TAW}-D_{r}}{\mathrm{TAW}-\mathrm{RAW}}=\frac{\mathrm{TAW}-D_{r}}{(1-p) \mathrm{TAW}} \\
\text { for } D_{r}>\mathrm{RAW}
\end{gathered}
$$

where TAW is the total depth of available soil water in the root zone (mm), RAW is the depth of readily available water in the root zone (mm), and $p$ is the fraction of TAW that a crop can extract from the root zone without suffering water stress. When $D_{r} \leq \mathrm{RAW}, K_{s m}=1.00$. The total available water in the root zone is estimated as the difference between the water content at field capacity and wilting point:

$$
\mathrm{TAW}=1,000\left(\theta_{f_{c}}-\theta_{w p}\right) z_{r}
$$

where $z_{r}$ is the effective rooting depth (m), and the 1,000 factor converts from $\mathrm{m}$ to $\mathrm{mm}$. RAW is estimated as:

$$
\mathrm{RAW}=p \mathrm{TAW}
$$

where RAW has the same units as TAW (mm).

A soil water balance for the root zone in terms of depletion is required to estimate daily $D_{r}$ (Allen et al., 1998, 2005 and ASCE, 2016):

$$
\begin{aligned}
D_{r, i} & =D_{r, i-1}-(P-R O)_{i}-I_{i} \\
& -C R_{i}+\mathrm{ET}_{a c t, i}+D P_{i}
\end{aligned}
$$

where $D_{r, i}$ is root zone depletion at the end of day $i(\mathrm{~mm})$, $D_{r, i-1}$ is root zone depletion at the end of the previous day, $i$ $1,(\mathrm{~mm}), P_{i}$ is precipitation on day $i(\mathrm{~mm}), R O_{i}$ is runoff from the soil surface on day $i(\mathrm{~mm}), I_{i}$ is net irrigation depth on day $i$ that infiltrates the soil $(\mathrm{mm}), C R_{i}$ is capillary rise from the groundwater table on day $i(\mathrm{~mm}), \mathrm{ET}_{a c t, i}$ is actual ET on day $i(\mathrm{~mm})$, and $D P_{i}$ is water loss out of the root zone by deep percolation on day $i(\mathrm{~mm})$.

Although soil water content might temporarily exceed field capacity following heavy rain or irrigation, in the previous equation the total amount of water exceeding field capacity is assumed to be lost the same day via deep percolation, following any ET for that day. This permits the extraction of one day's ET from this excess prior to percolation. That assumption can be modified by delaying the $D P$ used in equation 12 for several days. The root zone depletion will gradually increase due to ET and deep percolation. In the absence of a wetting event, the root zone depletion will ultimately reach the TAW value that is defined from rooting depth $\left(\theta_{f c}\right.$ and $\theta_{w p}$ in eq. 10). At that moment, no water is left for ET, and $K_{s m}$ becomes zero (from eq. 9). The limits imposed on $D_{r, i}$ are consequently:

$$
0 \leq D_{r, i} \leq \mathrm{TAW}
$$

To initiate the water balance for the root zone, the initial depletion $\left(D_{r, i-1}\right)$ can be derived from measured soil water content by:

$$
D_{r, i-1}=1,000\left(\theta_{f_{c}}-\theta_{i-1}\right) z_{r}
$$

where $\theta_{i-1}$ is the average soil water content at the end of day $i-1$ for the effective root zone, and the 1,000 factor converts from $\mathrm{m}$ to $\mathrm{mm}$. Following heavy rain or irrigation, the user can assume that the root zone is near field capacity, i.e., $D_{r, i-}$ $1 \approx 0$. Daily precipitation in amounts less than about $0.2 \mathrm{ET}_{o}$ is normally entirely evaporated and can generally be ignored in depletion calculations (in both the computation of $D_{r, i}$ and computation of $\mathrm{ET}_{\text {c act }}$ ) (Allen et al., 1998; ASCE, 2016). $I_{i}$ is equivalent to the mean infiltrated irrigation depth expressed for the landscape surface. Runoff from the surface during precipitation can be estimated using standard procedures from hydrologic texts.

\section{Capillary Rise (CR)}

The amount of water transported upward by capillary rise from the water table to the root zone or soil surface depends on the soil type, the depth of the water table, and the wetness of the root zone. $C R$ can normally be assumed to be zero when the water table is more than a few meters below the bottom of the root zone. Figures that can be used to estimate 
$\mathrm{CR}$ are available in the literature, e.g., Doorenbos and Pruitt (1977), Brutsaert (1982), and ASCE (2016).

\section{Deep Percolation from the Root Zone (DP)}

Following heavy rain or irrigation, the soil water content in the root zone may exceed field capacity. In application of equation $12, D P$ is assumed to occur within the same day of a wetting event, so that the depletion $D_{r, i}$ becomes zero. Therefore:

$$
D P_{i}=\left(P_{i}-R O_{i}\right)+I_{i}-\mathrm{ET}_{a c t, i}-D_{r, i-1}
$$

where $D P_{i}$ is limited to $D P_{i} \geq 0$. As long as the soil water content in the root zone is below field capacity (i.e., $D_{r, i}>$ 0 ), the soil is assumed to not drain and $D P_{i}=0$. If drainage from the root zone is expected to be delayed by a day or more following a large infiltration event, then daily $D P_{i}$ in equation 15 can be estimated as:

$$
\begin{aligned}
& D P_{i}= \\
& \max \left\{\min \left[\left(P_{i}-R O_{i}\right)+I_{i}-\mathrm{ET}_{a c t, i}-D_{r, i-1}, D R_{i}\right], 0\right\}
\end{aligned}
$$

where $D R_{i}$ is an expected maximum rate of drainage from the root zone on day $i$, with units for $D R_{i}$ the same as $P$ and $I$. Limiting $D P_{r, i}$ to $D R_{i}$ has the effect of causing $D P_{r, i}$ in equation 12 to be negative for one or more days. Values for $D R_{i}$ can be estimated from hydraulic conductivity characteristics for the root zone soil layer.

\section{Calculation of Average $\boldsymbol{K}_{\text {sm }}$}

Stress factor $K_{s m}$ equals 1.0 (for no ET reduction stress) for a period following irrigation (assuming that the irrigation depth was substantial) until the soil water depletion from the root zone exceeds RAW. Following that point in time, $K_{s m}$ progressively decreases until the next irrigation or precipitation event. The $K_{s m}$ just prior to the next event will be less than the $K_{s m}$ used in equation 2 because the $K_{s m}$ in equation 2 represents the average $K_{s m}$ over the entire interval or growing period.

Tables 4 and 5 list target values for the MAD fraction at the time of irrigation to produce the desired average managed $K_{s m}$ to be used in equation 2. The target values for MAD at the initiation of irrigation are a function of the depletion fraction $(p)$ when the particular vegetation begins to experience stress. Tables 4 and 5 represent two different strategies for implementing water stress and thereby reducing $K_{s m}$ to below 1.0. Table 4 assumes that irrigations are applied as infrequently as possible, with subsequent complete refilling of the root zone at each irrigation. The depth of water added to the root zone equals TAW from equation 10 multiplied by MAD. The complete refilling will result in a period following the irrigation event when there is no stress until the $p$ depletion level is reached and then with progressively increasing stress as the root zone continues to be depleted. The strategy in table 4 will minimize evaporation from the soil surface by extending the time between irrigation events, which is a commonly recommended practice (Harivandi et al., 2009). However, the plant appearance and performance may suffer because relatively extreme soil water depletion may be required prior to irrigation to obtain the average $K_{s m}$ target value over the total period between irrigations. In
Table 4. Management-allowed depletion (MAD) fraction to produce the stated managed stress factor $\left(K_{s m}\right)$ given the depletion fraction for no ET-reducing stress $(p)$ and assuming complete refilling of the root zone with each irrigation (MAD is expressed as a decimal). ${ }^{\text {a] }}$

\begin{tabular}{cccccc}
\hline & \multicolumn{5}{c}{ Depletion Fraction $(p)$ for No ET-Reducing Stress } \\
\cline { 2 - 6 }$K_{s m}$ & 0.3 & 0.4 & 0.5 & 0.6 & 0.7 \\
\hline 1.00 & 0.30 & 0.40 & 0.50 & 0.60 & 0.70 \\
0.95 & 0.47 & 0.57 & 0.66 & 0.75 & 0.86 \\
0.90 & 0.55 & 0.65 & 0.73 & 0.81 & 0.88 \\
0.85 & 0.62 & 0.71 & 0.79 & 0.86 & $-[\mathrm{b}]$ \\
0.80 & 0.68 & 0.76 & 0.83 & 0.89 & - \\
0.75 & 0.74 & 0.80 & 0.87 & - & - \\
0.70 & 0.78 & 0.84 & 0.89 & - & - \\
0.65 & 0.82 & 0.88 & - & - & - \\
0.60 & 0.86 & 0.90 & - & - & - \\
0.55 & 0.90 & - & - & - & - \\
0.50 & - & - & - & - & - \\
\hline
\end{tabular}

a] Data are from the Irrigation Association (IA, 2003, 2011).

[b] “." indicates that the MAD value approaches or exceeds 1 , so the soil water content approaches or exceeds the permanent wilting point and the vegetation is in danger of dormancy or death.

some cases, the vegetation may enter temporary or permanent dormancy when MAD is set at high values.

In contrast, the strategy in table 5 endeavors to establish a controlled, more continuously sustained level of water stress in which the soil water content is held within a range that is near a target value that produces some water stress. This strategy can be implemented in an automated, soil water sensor-based irrigation system by applying frequent, small doses of water but with the trigger soil water level (MAD) set to a dry level. However, the percentage of water lost by evaporation from the soil surface increases as the irrigation frequency increases, especially when the irrigation doses are small and sprinkler irrigation is used. Therefore, evaporation of water from the soil surface, which is not nearly as effective as transpiration through the plant system for sustaining vegetation health and appearance, will be greater with this second strategy, and the degree of water conservation will likely be less than with the first strategy, in which increasing irrigation doses and the time between irrigations is beneficial to overall water conservation.

Table 5. Average management-allowed depletion (MAD) fraction to produce the stated managed stress factor $\left(K_{s m}\right)$ given the depletion fraction for no ET-reducing stress $(p)$ and assuming only partial refilling of the root zone with each irrigation, where the depletion between events is managed to range from MAD -0.1 to MAD +0.1 (MAD is expressed as a decimal). ${ }^{[a]}$

\begin{tabular}{cccccc}
\hline & \multicolumn{5}{c}{ Depletion Fraction $(p)$ for No Stress } \\
\cline { 2 - 6 }$K_{s m}$ & 0.3 & 0.4 & 0.5 & 0.6 & 0.7 \\
\hline 1.00 & 0.20 & 0.30 & 0.40 & 0.50 & 0.60 \\
0.95 & 0.30 & 0.39 & 0.48 & 0.57 & 0.66 \\
0.90 & 0.35 & 0.44 & 0.53 & 0.61 & 0.69 \\
0.85 & 0.39 & 0.47 & 0.56 & 0.64 & 0.72 \\
0.80 & 0.43 & 0.51 & 0.58 & 0.66 & 0.74 \\
0.75 & 0.46 & 0.54 & 0.61 & 0.68 & 0.76 \\
0.70 & 0.50 & 0.57 & 0.64 & 0.70 & $-[\mathrm{b}]$ \\
0.65 & 0.53 & 0.59 & 0.66 & 0.72 & - \\
0.60 & 0.57 & 0.62 & 0.68 & 0.74 & - \\
0.55 & 0.60 & 0.66 & 0.71 & 0.76 & - \\
0.50 & 0.64 & 0.68 & 0.73 & - & - \\
0.45 & 0.67 & 0.71 & 0.76 & - & - \\
0.40 & 0.70 & 0.74 & - & - & - \\
0.35 & 0.74 & - & - & - & - \\
\hline
\end{tabular}

[a] Data are from the Irrigation Association (IA, 2003, 2011).

[b] "-" indicates that the MAD value approaches or exceeds 1, so the soil water content approaches or exceeds the permanent wilting point and the vegetation is in danger of dormancy or death. 
Some vegetation types, such as turfgrass, may benefit from the full-replenishment strategy, when the grass has the opportunity to periodically recover from stress and produce new growth and vigor that maximizes density and discourages weed growth. Sustained stress to turf, as under the strategy in table 5, may cause some degradation in turf health over time, with reduced turf density and increased opportunities for weed invasion. Shrubs and trees are expected to exhibit different behaviors.

The values for MAD in table 4 were derived by integrating equation 9 over a range of depletion $\left(D_{r}\right)$ values, from 0 to MAD, that produced an average value for $K_{s}$ equal to the target $K_{s m}$. The values in table 5 were derived by integrating equation 9 over a range from MAD -0.1 to $\mathrm{MAD}+0.1$ that produced an average value equal to $K_{s m}$ and represents attempts to maintain root zone water at levels that continuously and consistently create some stress-based reduction to $K_{L}$. Users can modify tables 4 and 5 for specific vegetation types or species when information is available. The values for MAD in the tables exceed the values for $p$ where stress is first initiated. More research is needed on assessing the best methods to reduce landscape ET and yet retain acceptable or desirable plant health and appearance. Research is also needed to assess or confirm total ET requirements by the two strategies or by a mixture of strategies.

A review of tables 4 and 5 shows the differences in the extent of MAD required to produce average, target values for $K_{s m}$ between the two strategies. For example, for a $p$ of 0.5 (indicating that water stress begins at a soil water depletion level of $50 \%$ ) and a target $K_{s m}$ of 0.8 , table 4 suggests that the MAD prior to full irrigation needs to be 0.83 . This indicates that relatively severe stress needs to occur prior to irrigation to achieve an average $K_{s m}$ of 0.8 . Depleting soil water to 0.83 of available water may be considered risky in that, by definition, a depletion of 1.0 will result in permanent wilting and generally plant dormancy or death.

In contrast, for the same $p=0.5$ and $K_{s m}=0.8$, table 5 suggests that a targeted and sustained MAD of 0.58 prior to a lighter irrigation can achieve the same $K_{s m}$. Given the MAD -0.1 to MAD + 0.1 range used to develop table 5 , the maximum MAD prior to irrigation for table 5 would be 0.58 $+0.1=0.68$. The MAD $=0.68$ value represents about 0.15 less stress to the vegetation prior to irrigation as compared to $\mathrm{MAD}=0.83$ from table 4 . However, it keeps the vegetation in a continuously stressed condition, which may or may not be desired. Given a rooting depth of $0.5 \mathrm{~m}$ and waterholding capacity of $0.1 \mathrm{~m} \mathrm{~m}^{-1}$, so that TAW $=0.5 \times 0.1=$ $0.05 \mathrm{~m}$, the strategy in table 4 would add TAW $\times \mathrm{MAD}=$ $0.05 \times 0.83=0.042 \mathrm{~m}(42 \mathrm{~mm})$ of net water depth with each irrigation. The strategy in table 5 would add $0.05 \times 0.2=$ $0.01 \mathrm{~m}(10 \mathrm{~mm})$ of water to the root zone with each irrigation. As a result, the strategy in table 5 would require at least four times as many irrigations, with associated evaporation losses from intercepted water on plant leaves and the soil surface that would increase the overall ET consumption and reduce some of the benefits of the strategy.

Methods to estimate total ET that include evaporation following wetting are described later in the section titled Impact of Canopy Wetting and Irrigation Frequency on $K_{L}$. In general, increasing irrigation doses and the time between irrigations will reduce total ET consumption by reducing evaporation occurring after each irrigation event. This supports common recommendations to professional landscape irrigation managers and home gardeners to irrigate "deep and infrequently" (Qian and Fry, 1996; McDonald, 1999; Richie et al., 2002; Jordan et al., 2003; Lee, 2014).

The +0.1 to -0.1 range used to derive table 5 can be expanded to stretch irrigation events further apart. The result will be targeted MAD levels that are closer to those of table 4 .

\section{ACTUAL ET FROM LANDSCAPES}

Equations 2 and 3 provide target estimates for $K_{L}$ that can be used for planning and water management, where $K_{L}$ can contain an explicit and intentional amount of managed stress for purposes of water conservation. The degree of implied managed stress is quantified in equation 2 by the $K_{s m}$ term and provides a target $K_{L}$ to accomplish the stress-induced reduction in ET. In practice, actual water management may result in a $K_{L}$ value at which the water stress is greater or less than the targeted managed stress. When conducting water balances for landscapes, determination of the actual water consumption is required. Under those situations, the managed stress coefficient $\left(K_{s m}\right)$ in equations 2 or 3 needs to be replaced by an actual stress coefficient $\left(K_{s}\right)$, where $K_{s}$ is computed using equations 7 or 9 based on soil water depletion determined from a daily balance of root zone soil water or is estimated from soil water measurements. Equation 2 then takes the form:

$$
K_{L \text { act }}=K_{v} K_{d} K_{s} K_{m c}
$$

where $K_{s m}$ in equation 2 is replaced by an actual stress coefficient $\left(K_{s}\right)$, and $K_{\text {Lact }}$ is the actual ET from the landscape under actual water availability. Equation 3, which includes a separate estimate for evaporation from soil, becomes:

$$
K_{L \text { act }}=\left[\left(1-K_{d}\right) K_{\text {soil }}+K_{v} K_{d} K_{s}\right] K_{m c}
$$

Actual ET from the landscape under actual watering conditions is:

$$
\mathrm{ET}_{L \text { act }}=K_{\text {L act }} \mathrm{ET}_{o}
$$

$K_{s}$ can be estimated from equations 7 or 9 , where the depletion fraction $(p)$, used to estimate RAW, is set to specific values determined for the species, if those values are available. Actual rates and timing of irrigation and precipitation are required. The effective depth of the root zone, used to estimate TAW, can be species or variety specific, and therefore obtaining information specific to the variety is important. Trees tend to develop lateral roots growing parallel to the surface of the soil. Factors affecting rooting depth, root density, and spread of roots include soil texture and compaction, depth to the water table, fertility, and soil water content (Gilman, 1990a), as well as the depth and extent mulching (Greenly and Rakow, 1995). Some research has reported impacts of wetting amounts and frequency on rooting development, so past irrigation history should also be considered (Gilman, 1990b). The vegetation coefficient $\left(K_{v}\right)$ described 
in table 1 represents the landscape $K_{L}$ under a water supply that is sufficient to support full ET and having somewhat dense vegetation with near-maximum ground cover and open environmental exposure.

The daily soil water balance required to calculate $K_{L \text { act }}$ with equations 17 or 18 can be scripted into software applications and even into future smart irrigation controllers that can make daily calculations for $K_{L \text { act }}$ and $\mathrm{ET}_{L \text { act }}$ based on actual irrigation schedules and reported $\mathrm{ET}_{o}$ and precipitation. Those estimates for $\mathrm{ET}_{\text {Lact }}$ can be compared with irrigation volumes or depths applied by the irrigation controllers to better inform water users on the performance of their systems.

\section{Impact of Canopy Wetting and Irrigation Frequency on $\boldsymbol{K}_{L}$}

Wetting of landscape vegetation by irrigation or rainfall can substantially increase the potential ET from the landscape due to the combined influence of evaporation from exposed wet soil and evaporation from water intercepted by vegetation during the wetting event, if by rainfall or sprinkler. The more frequent the wetting events, the greater the potential ET rate. Landscape irrigation is often accomplished with automatic controllers that are easily set to irrigate frequently, even daily. Water that is intercepted and retained on the vegetation surfaces is freely evaporated during and following a wetting event, even if the underlying vegetation is experiencing some level of water stress and the soil is dry. Evaporation of intercepted water can occur even with nighttime irrigation, with evaporation from wet plant canopies and soil surface occurring the following day.

The impact of evaporation from exposed soil among vegetation when the density coefficient is $K_{d}<1$ is accounted for using equations 3 and 18 with figure 2, or when coupled with estimates for $K_{\text {soil }}$ from a daily soil surface evaporation model such as provided by Allen et al. (1998) and ASCE (2016). Evaporation of intercepted water by plant canopies generally takes precedence over transpiration and evaporation from exposed soil because intercepted water is a free water surface with little or no surface resistance. Generally, evaporation of intercepted water will raise the $K_{L}$ to a maximum $K_{L \text { max }}$ that is limited by the energy available to convert liquid water to vapor. The potential increase in $K_{L}$ from evaporation of intercepted water can be estimated as:

$$
K_{\text {Int }}=\frac{S}{t_{w} \mathrm{ET}_{o}}
$$

where $S$ is the depth of intercepted water collecting on vegetation leaves from a precipitation or irrigation event $(\mathrm{mm}), t_{w}$ is the time between wetting events (days), and $\mathrm{ET}_{o}$ has units of $\mathrm{mm} \mathrm{d}^{-1} . K_{\text {Int }}$ represents the additional amount of evaporation added to the normal landscape ET, in the form of a landscape coefficient component. An adjusted $K_{L}$ that incorporates the impacts of interception losses is calculated as:

$$
\begin{aligned}
K_{L} & =K_{L e q .2 o r 3} \\
& +K_{m c} \min \left[K_{d} K_{\text {Int }},\left(K_{L \max }-K_{L \text { eq. } 2 \text { or } 3}\right)\right]
\end{aligned}
$$

where $K_{L \text { eq. } 20 \text { r } 3}$ represents the $K_{L}$ estimated by equations 2 or 3 , and $K_{L \text { max }}$ is the maximum limit imposed on $K_{L}$, estimated from equation 22 . The $K_{d}$ term accounts for only vegetation having interception losses, with wetting of the soil assumed to be accounted for by the $K_{\text {soil }}$ factor of equation 3 . The $K_{m c}$ term increases or decreases the overall adjustment according to the local microclimate environment. Values for $S$ are typically about $1 \mathrm{~mm}$ for trees and about 0.5 to $1 \mathrm{~mm}$ for turf (Hoffman et al., 1992; Breuer et al., 2003). These losses are relatively small compared to total $\mathrm{ET}_{L}$ when wetting events are relatively infrequent, but they can become substantial when irrigation or precipitation intervals $\left(t_{w}\right)$ are smaller than three or four days. For example, on an annual basis, these evaporative losses can be a significant factor in forest hydrology, ranging from $20 \%$ to $40 \%$ of total ET for conifer forests and from $10 \%$ to $20 \%$ for hardwood forests (Zinke, 1967). In the application of equation 21 , the limits $K_{L}=$ $K_{v} K_{d} K_{m c} K_{s m} \leq K_{L \text { max }}$ are applied. Equation 21 can be similarly used to adjust the estimate for $K_{L \text { act }}$ in equations 17 or 18 for interception losses by substituting $K_{L \text { act }}$ for $K_{L}$ in the right side of equation 21 .

$K_{L \max }$ in equation 21 represents the maximum expected value for $K_{L}$ following rain or irrigation, under conditions of either bare soil or some degree of vegetation cover. The value for $K_{L \text { max }}$ is governed by the amount of energy available for evaporation from the sun, atmosphere, and soil. Given energy availability constraints, and the definition of $K_{L}$ as the ratio of $\mathrm{ET}_{L}$ to $\mathrm{ET}_{o}$, the value for $K_{L \max }$ is generally not expected to exceed 1.2 to 1.3 relative to the clipped grass reference. Following Allen et al. (1998), where the maximum $K_{L}$ for the $\mathrm{ET}_{o}$ basis is impacted by the height of the landscape vegetation and by average levels of wind speed and relative humidity:

$$
\begin{aligned}
& K_{L \max }= \\
& 1.2+\left[0.04\left(u_{2}-2\right)-0.004\left(\mathrm{RH}_{\text {min }}-45\right)\right]\left(\frac{h}{3}\right)^{0.3}
\end{aligned}
$$

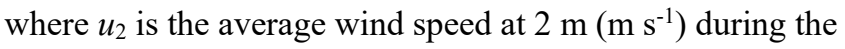
month or period, $\mathrm{RH}_{\text {min }}$ is the average daily minimum relative humidity (\%) during the month or period, and $h$ is the mean plant height $(\mathrm{m})$ during the period of calculation. The 1.2 term in equation 22 is an expected landscape coefficient for tall, leafy vegetation, under moderate wind speed and $\mathrm{RH}$, that has a wet leaf surface from intercepted irrigation or rain. The 1.2 value is similar to the crop coefficient value for crops used for tall agricultural crops such as alfalfa or maize (Allen et al., 1998) relative to the clipped grass reference. The estimate for $K_{L \max }$ will increase under strong wind and/or low RH.

The $\min ()$ argument in equation 21 limits the maximum value for $K_{L}$ to $K_{L \max }$. Equation 21 is a good approximation for total $K_{L}$ that considers leaf wetting by interception when equations 2 or 18 are used and where $K_{v}$ includes averaged effects of evaporation from the soil surface. Using equation 21 with equation 3 additionally includes impacts of evaporation from exposed soil that is influenced by wetting frequency. 
The effect on $K_{L}$ by evaporation of intercepted water from vegetation is illustrated in table 6 , where evaporation of intercepted water on vegetation from sprinklers and evaporation from wet soil between plants are both considered. In table 6, equation 21 is applied to a range of $K_{v} K_{d} K_{s m} K_{m c}$ using equation 3 under two levels of $\mathrm{ET}_{o}$ and under four irrigation intervals $(1,2,3$, and 7 days). Interception depth $(S)$ was assumed to be $1 \mathrm{~mm}, K_{m c}=1.0$, and $K_{L \max }=1.2$. Estimates for $K_{\text {soil }}$ were taken from figure 2 . The effect of evaporation of intercepted water on $K_{L}$ is most pronounced for daily watering intervals and at lower values for $K_{d}$, impacting $K_{v} K_{d} K_{s m} K_{m c}$ and the influence of wet soil. Two entries are shown in table 6 for $K_{v} K_{d} K_{s m} K_{m c}=0.80$, where $K_{d}=1.00$ and 0.8 . These two values for $K_{d}$ correspond to (1) full surface cover, as for turfgrass, and (2) a landscape having approximately $20 \%$ exposed soil, e.g., for dense ornamentals, and where $K_{v}$ has a larger value than for turfgrass and that counters the impact of $K_{d}$. The effect of wet soil among vegetation without complete groundcover increased $K_{L}$ slightly for a daily wetting frequency due to the high estimate for $K_{\text {soil }}$ Impacts of irrigation frequency, represented by $t_{w}$, are largest when $K_{v} K_{d} K_{s m} K_{m c}$ is lowest because more energy is available for evaporating intercepted water and water from exposed soil. The impact of evaporation from soil is low when $K_{d}$ is high because transpiration dominates. The $K_{L}$ estimated by equation 21 using equation 3 is similar under all wetting frequencies when $K_{v} K_{d} K_{s m} K_{m c}$ is high (e.g., 1.1) because most of the available energy is already used by relatively high transpiration. The impact of decreasing the irrigation interval from 7 days to 1 day was only 0.08 on $K_{L}$ when $K_{v} K_{d} K_{s m} K_{m c}$ was already 1.1. The impact is much greater under lower $K_{v} K_{d} K_{s m} K_{m c}$, which is where conservation is more likely to be occurring.

\section{Example of Applying Table 6 for Water Conservation in Turf}

As an example of the impacts of wetting frequency considering both plant interception losses and soil water evaporation, equation 3 estimates daily watering to increase $K_{L}$ to 1.05 as compared with $K_{L}=0.88$ for watering every three days and $K_{L}=0.84$ for weekly watering for typical turfgrass under moderately low $\mathrm{ET}_{o}=4 \mathrm{~mm} \mathrm{~d}^{-1}$ and where $K_{d}=1.0$, $K_{m c}=1.0$, and $K_{s m}=0.9$ (mild imposed stress). In this case, $K_{v} K_{d} K_{s m} K_{m c} \approx 0.8$, with $K_{L}$ from equation 21 using $K_{L \text { eq.2or3 } 3}$. This suggests a $25 \%$ increase in water consumption under these conditions when the watering frequency is increased from weekly to daily. When $\mathrm{ET}_{o}$ is increased to $8 \mathrm{~mm} \mathrm{~d}^{-1}, K_{L}$ increases from 0.82 to 0.93 , or by $13 \%$, when shifting from weekly to daily irrigation. This is a smaller percentage increase than for $\mathrm{ET}_{o}=4 \mathrm{~mm} \mathrm{~d}^{-1}$ because the amount of daily interception $(1 \mathrm{~mm})$ becomes smaller compared with the greater total daily ET rate.

The example values in table 6 support increasing intervals between watering events to conserve water. However, users need to recognize constraints on long time intervals between watering events imposed by maximum water dosage rates to limit surface runoff on low-intake soils. In addition, such practices on lighter, fast-draining soils can lead to percolation below the root zones of shallow-rooted plants. Table 6, with important constraints under certain soil and rooting conditions, should provide useful information for end-users and water managers.

\section{ESTIMATES OF $K_{L}$ DURING WINTER AND NONGROWING SEASONS}

Estimation of ET during winter or nongrowing periods can be important for annual water balances used in hydrologic studies and for estimation of accruals to soil water from precipitation during a nongrowing season. Nongrowing periods are defined as periods during which the landscape is dormant due to very cold or freezing conditions, most vegetation senesces to dead material, and deciduous trees drop leaves. In temperate climates, nongrowing periods include periods of frost and may represent continuously frozen conditions.

\section{Types of Surface Conditions During Nongrowing Periods}

The type and condition of the landscape surface during nongrowing periods dictate the range for $\mathrm{ET}_{L}$. When the surface is bare soil, then $K_{L}$ will be similar to the $K_{\text {soil }}$ estimated from figure 2 or using equations 10 to 18 of ASCE (2016). When dead or dormant vegetation or some type of organic mulch or plant residue covers the surface, evaporation rates generally decrease, and $K_{L}$ will be lower than $K_{\text {soil }}$. When active weed growth or volunteer plants cover the surface, $K_{L}$ will vary according to the leaf area or fraction of ground covered by the vegetation and by the vegetation vigor. In this case, $K_{L}$ can be estimated by equation 3 using $K_{d}$ from equation 4 , and by the availability of soil water. When the surface is snow-covered or frozen, then $K_{L}$ is difficult to estimate, and a low, constant value for $\mathrm{ET}_{L}$ may have to be assumed. Additional recommendations and estimating procedures are given in chapter 10 of ASCE (2016).

\section{Bare Soil}

The frequency and amount of precipitation will strongly influence $K_{L}$ when the ground is mostly bare following harvest or other removal of vegetation, and $K_{L}$ can be calculated as $K_{L}=K_{\text {soil }}$ using figure 2 or using equations 10 to 18 of

Table 6. Estimated $K_{L}$ values from equation 21 using equation 3 for different levels of $K_{v} K_{d} K_{s m} K_{m c}$, two levels of ET ${ }_{o}$, and for irrigation intervals $\left(t_{w}\right)$ of $1,2,3$, and 7 days with $K_{\text {soil }}$ values from figure $2 .{ }^{[a]}$

\begin{tabular}{|c|c|c|c|c|c|c|c|c|c|}
\hline \multirow[b]{2}{*}{$K_{\vee} K_{d} K_{s m} K_{m c}$} & \multirow[b]{2}{*}{$K_{d}$} & \multicolumn{4}{|c|}{$\mathrm{ET}_{\mathrm{o}}=4 \mathrm{~mm} \mathrm{~d}^{-1}$} & \multicolumn{4}{|c|}{$\mathrm{ET}_{\mathrm{o}}=8 \mathrm{~mm} \mathrm{~d}^{-1}$} \\
\hline & & $\begin{aligned} t_{w} & =1, \\
K_{\text {soil }} & =1.1\end{aligned}$ & $\begin{array}{c}t_{w}=2, \\
K_{\text {soil }}=0.9\end{array}$ & $\begin{aligned} t_{w} & =3, \\
K_{\text {soil }} & =0.7\end{aligned}$ & $\begin{aligned} t_{w} & =7, \\
K_{\text {soil }} & =0.35\end{aligned}$ & $\begin{aligned} t_{w} & =1, \\
K_{\text {soil }} & =0.85\end{aligned}$ & $\begin{aligned} t_{w} & =2, \\
K_{\text {soil }} & =0.8\end{aligned}$ & $\begin{aligned} t_{w} & =3, \\
K_{\text {soil }} & =0.55\end{aligned}$ & $\begin{aligned} t_{w} & =7, \\
K_{\text {soil }} & =0.3\end{aligned}$ \\
\hline 1.1 & 1.00 & 1.20 & 1.20 & 1.18 & 1.14 & 1.20 & 1.16 & 1.14 & 1.12 \\
\hline 1 & 1.00 & 1.20 & 1.13 & 1.08 & 1.04 & 1.13 & 1.06 & 1.04 & 1.02 \\
\hline 0.8 & 1.00 & 1.05 & 0.93 & 0.88 & 0.84 & 0.93 & 0.86 & 0.84 & 0.82 \\
\hline 0.8 & 0.80 & 1.06 & 0.92 & 0.85 & 0.74 & 0.91 & 0.80 & 0.76 & 0.69 \\
\hline 0.6 & 0.60 & 0.95 & 0.80 & 0.69 & 0.52 & 0.78 & 0.62 & 0.57 & 0.45 \\
\hline 0.4 & 0.50 & 0.88 & 0.71 & 0.59 & 0.39 & 0.69 & 0.51 & 0.45 & 0.31 \\
\hline
\end{tabular}

[a] For interception depth $S=1 \mathrm{~mm}$ and $K_{L \max }=1.2 ; K_{\text {soil }}$ was selected from the top graph of figure 2 using $\mathrm{ET}_{o}$ and $t_{w}$. 
ASCE (2016). The $K_{L}$ varies with the frequency of wetting events and magnitude of $\mathrm{ET}_{0}$. Martin and Gilley (1993) and Allen et al. (1998) recommended this approach, and Snyder and Eching (2005) used a similar approach in the LIMP software to estimate a $K_{L}$ during winter that was then melded with a $K_{L}$ curve for the growing season. When a daily soil water balance is applied, the user may elect to apply the dual or basal $K_{c b}$ approach (Allen et al., 1998; ASCE, 2016). During long dormant periods with little or no precipitation, the topsoil layer may dry to very low water contents. This provides the opportunity for $\mathrm{ET}_{L}=0$ during long periods of no rainfall.

\section{Surface Covered with Dead Vegetation}

Dead plant residue and mulches reduce soil evaporation by providing a mechanical barrier to aerodynamic forces and shielding the soil surface from solar radiation. Mulches also reduce the connection between liquid or vapor in the soil and the air above (Burt et al., 2005). When the ground surface has a plant residue or other dead organic mulch cover, or when part of the unharvested crop remains suspended above the surface in a dead or senesced condition, then the surface will respond similarly to a surface covered by mulch. In this case, $K_{L}$ can be set equal to $K_{\text {soil }}$ as estimated from figure 2 or from equations 10 to 18 of ASCE (2016) with the value for $K_{\text {soil }}$ reduced by about $5 \%$ for each $10 \%$ of soil surface that is effectively covered by organic mulch (Allen et al., 1998). Evaporation from dead, but wet, vegetation can be substantial for a few days following a precipitation event.

\section{Surface Covered with Live Vegetation}

During frost-free periods following death or dormancy of landscape vegetation, weeds may germinate and grow. This vegetation extracts water from storage within the soil profile and from any rainfall. In addition, flower or garden seeds lost during harvest may germinate following rainfall events and will add to the ground cover. The amount of ground surface covered by vegetation will depend on the severity of weed infestation, the density of the volunteer vegetation, the frequency and extent of soil tillage, the availability of soil water or rain, and any damage by frost. The total value for $K_{L}$ will depend primarily on the value estimated for $K_{d}$. The value for $K_{d}$ during the nongrowing period is estimated over time according to the amount of vegetation covering the surface using equations 4 to 6 or from remote-sensing images by way of a vegetation index (Neale et al., 2005; Glenn et al., 2010).

The $K_{L}$ for vegetation during the nongrowing period is limited by the amount of soil water available to supply ET to satisfy the law of conservation of mass. Under all conditions, the integration of $K_{L} \mathrm{ET}_{o}$ over the course of the nongrowing period cannot exceed the sum of precipitation occurring during the period plus any residual soil water in the root zone at the end of the growing season that can be subsequently depleted by the vegetation plus any upward flow from a shallow saturated system. The root zone in this case is the root zone for the weeds or volunteer vegetation. A daily soil water balance may provide the best estimate of soil water-induced stress and associated reductions in $K_{L}$ and $\mathrm{ET}_{L}$.

\section{Frozen or Snow-Covered Surface}

When the ground surface is snow-covered or frozen, any vegetation will be largely unresponsive and will not contribute directly to $\mathrm{ET}_{L}$. In this situation, $\mathrm{ET}_{L}$ is closely related to the availability of free water at the surface and to the albedo of the surface. The albedo of snow-covered surfaces can range from 0.40 for old, dirty snow cover to 0.90 for fresh, dry snow (ASCE, 2016). Therefore, the $\mathrm{ET}_{L}$ for snow cover will be less than $\mathrm{ET}_{o}$ because $25 \%$ to $85 \%$ less shortwave energy is available. In addition, some energy must be used to melt snow before evaporation in addition to the energy consumed in producing melted liquid that seeps into the snowpack.

Wright (1993), as summarized in ASCE (2016), measured $\mathrm{ET}_{\text {act }}$ averaging $1 \mathrm{~mm} \mathrm{~d}^{-1}$ over nongrowing periods at Kimberly, Idaho, that were six months long (1 October to 30 March). The latitude of Kimberly is $42^{\circ} \mathrm{N}$, and the elevation is about $1200 \mathrm{~m}$. Over the six-year study period, the ground was at least $50 \%$ covered by snow for $25 \%$ of the time from 1 October to 30 March. The ground, when exposed, was frozen about $50 \%$ of the time. The $K_{c}$ averaged 0.25 during periods when the soil was not frozen but where frosts occurred (October and early November). When the ground had 50\% or greater snow cover, $\mathrm{ET}_{c}$ averaged only $0.4 \mathrm{~mm} \mathrm{~d}^{-1}$. Wright found that over the six-month nongrowing period, total cumulative $\mathrm{ET}_{c}$ exceeded precipitation by about $50 \mathrm{~mm}$, indicating a drying soil.

\section{Procedure in ASABE STANDARd S623}

The IA decoupling procedure outlined in previous sections is a useful engineering framework for aggregated landscape water requirement estimates. ASABE Standard S623 (ASABE, 2017) contains a simplified procedure to estimate net plant water requirements for established landscape materials. ASABE Standard S623 was developed by a team representing industry and academia and is applicable to peak growing season requirements for several broad plant types that are well established in the landscape. ASABE recognized the need for a broad summary of coefficients (e.g., $K_{L}$ ) readily usable by diverse landscape practitioners. The standard recommends plant factors (PFs, equivalent to $K_{v}$ ) for turfgrasses, herbaceous perennials, annual flowers, woody plants, and desert plants, as shown in table 7, for the minimum water requirement needed to maintain acceptable landscape appearance and function.

In particular, ASABE Standard S623 provides the landscape design community, water management agencies that plan and enforce conservation programs, and landscape

Table 7. Annual average fraction of ET $T_{o}$ (i.e., $K_{L}$ ) from ASABE Standard S623 (ASABE, 2017) for acceptable plant appearance.

\begin{tabular}{cc}
\hline Plant Type & $\begin{array}{c}\text { Recommended } \\
\text { Plant Factor }\end{array}$ \\
\hline Cool-season turf & 0.8 \\
Warm-season turf & 0.6 \\
Annual flowers & 0.8 \\
Woody plants and herbaceous perennials, wet ${ }^{[\mathrm{a}]}$ & 0.7 \\
Woody plants and herbaceous perennials, dry & 0.5 \\
Desert plants & 0.3 \\
\hline [a] For tropical plants having precipitation in most months, a plant factor \\
of 0.7 applies. Where monsoonal climates are present, 0.7 applies for \\
the wet season, and 0.5 applies for the dry season.
\end{tabular}


managers with a simple and practical tool to estimate water requirements of landscapes with mixed turf and non-turf plant types. As such, a landscape is portioned into hydrozones (Kjelgren et al., 2016) based on the design and controlled by a single solenoid valve connected to a time clock. The PF for a hydrozone is dictated by the plant type having the highest water requirements (Davis and Dukes, 2010). For example, a woody plant imbedded in a primarily turfgrass hydrozone would be irrigated using a warm-season or coolseason PF. The water requirement of the total landscape is an aggregate $\mathrm{PF}$ weighted by hydrozone area.

In ASABE Standard S623, the target turf and perennial/ground cover PFs are functionally similar to the IA $K_{v}$ values in table 1, apart from warm-season turf being somewhat lower due its inherently more efficient C4 photosynthesis and ability to tolerate higher levels of water stress (Romero and Dukes, 2016). The greatest difference is in the woody PF values. Currently, there are not enough data, nor industry ability in practice, to separate water use and PF for trees from shrubs, but the literature supports distinguishing woody species based on their stomatal response to dry air. Freestanding, well ventilated woody species typical of most landscapes have stomates closely coupled and sensitive to dry air (Jarvis and McNaughton, 1986). Increased crown ventilation means that woody plant stomates must exercise more direct control over transpiration than low, dense canopies (Goldberg and Bernhofer, 2008), and in high vapor pressure deficits (VPD) environments plants partially close their stomates to moderate transpiration (Choudhury and Monteith, 1986). High VPD environments are common in semi-arid to arid regions, such as much of the western U.S., and hence PF values are lower for woody landscape species in those regions. Similarly, PF values for desert species are lower because they can meet landscape appearance and performance expectations through their evolutionary adaptation to limited water by uncoupling water use from the atmospheric factors that drive $\mathrm{ET}_{o}$. For example, cacti species with crassulacean acid metabolism (Kluge and Ting, 2012) transpire at night, and other desert species transpire freely after rainfall, but tolerate high $\mathrm{ET}_{o}$ conditions through partial stomatal closure, desiccation-tolerant leaves, and deep-root water extraction.

The ASABE Standard S623 equivalent to equation 2 is:

$$
K_{L}=\operatorname{PF}\left(K_{d}\right)
$$

where $K_{s m}$ and $K_{m c}$ coefficients are factored into the PF value, and $K_{d}$ equals 1.0 when the fraction of ground cover $\left(f_{c}\right)$ exceeds 0.80 (Kjelgren et al., 2016). Similar but expanded values for PF for use in California have been proposed by the University of California Division of Agriculture and Natural Resources (UCANR, 2020) via the SLIDE calculator (https:// ucanr.edu/sites/UrbanHort/Water_Use_of_Turfgrass_and_Landscape_Plant Materials/SLIDE_Simplified__ Irrigation_Demand_Estimation/). The University of The University of The University of California values were adopted from ASABE Standard S623 (ASABE, 2017) and Kjelgren et al. (2016); the latter provides an extensive list of values for PF for trees, shrubs, and other ground covers.
The procedure in ASABE Standard S623 and the IA procedure are complementary. Both use a vegetation type and density system as the basis for efficiently estimating scientifically accurate landscape water requirements. The PFs in ASABE Standard S623 do not directly compare to the $K_{L}$ values presented by Kjelgren et al. (2016) and in table 6 because they depend on the mixture of plant types in a landscape. However, they align functionally when $K_{L}$ is 0.80 for all turf landscapes and for mixed woody plant-turf landscapes in a humid climate. A $K_{L}$ of 0.6 aligns with the water requirements of a mixed turf-woody landscape in an arid climate. In both cases, the lower $K_{L}$ values have some degree of soil water stress explicitly addressed in the IA procedure, as opposed to implicitly embedded in the PFs of ASABE Standard S623.

\section{USE OF High-Resolution Aerial REMote SENSING DATA TO ESTIMATE $K_{L}$}

The use of high-resolution aerial remote sensing data can assist in $K_{v}$ estimation, where $K_{v}$ or $K_{L}$ is approximated from vegetation indices that indicate the amount of vegetation present in a landscape. A common vegetation index is the normalized difference vegetation index (NDVI), which calculates a normalized difference between the red and near-infrared (NIR) reflectance from a surface (Tucker, 1979; Carlson and Ripley, 1997).

Currently, a relatively high-resolution $(1 \mathrm{~m})$ aerial data set that covers the U.S. and is free to use is the North American Imaging Program (NAIP) data set (https://www.fsa.usda.gov/programs-and-services/aerialphotography/imagery-programs/naip-imagery/). The NAIP imagery is collected approximately every three years across the U.S. during midsummer. A weakness of the NAIP data set is that it represents only a single snapshot of vegetation amounts and only about every three years. A strength is that imagery collected during midsummer can be a good representative sample of landscapes and that the data are free. Another strength of NAIP is that the red and NIR bands can be used to calculate the NDVI. However, the NAIP data, which are reported as 8-bit digital numbers that are scaled differently between the red and NIR bands, must be calibrated into equivalent surface reflectances prior to computing NDVI so that NDVI values are consistent among the $6 \mathrm{~km} \times 6 \mathrm{~km}$ NAIP scenes and can be related to $K_{L}$ values.

Kilic et al. (2017) developed a procedure for converting NAIP digital numbers (DN) to surface reflectance by calibrating against surface reflectance derived from Landsat and Sentinel 2 satellites. The surface reflectance was then used to estimate NDVI at $1 \mathrm{~m}$ scale for residential areas and to classify NAIP images into turf, trees, shadows, and impervious areas. The NDVI estimates were used to estimate $K_{L}$ with a linear equation (http://appgearup.appspot.com/). Multiplication of $K_{L}$ by $\mathrm{ET}_{o}$ produced maps of water consumption at the $1 \mathrm{~m}$ scale. An example of an aerial image and resulting map of landscape water consumption is shown in figure 4. The GEARUP application, which operates on the Google Earth engine, uses maps of water consumption to provide information to homeowners on managing residential water scheduling (Kilic et al., 2017). 


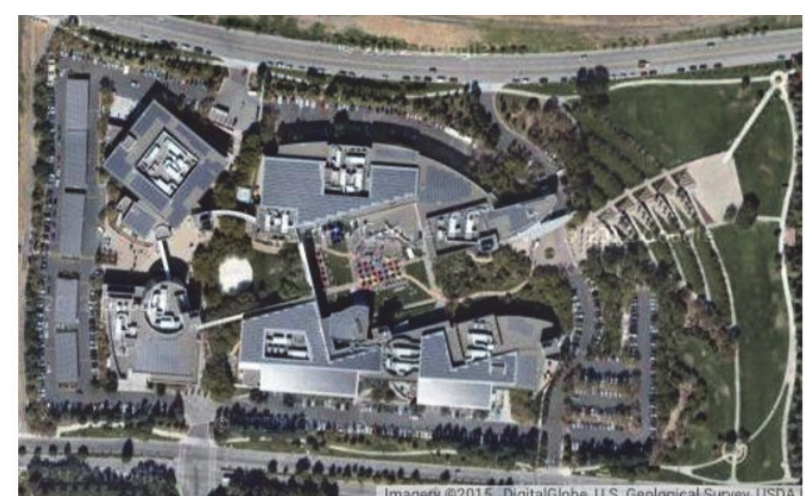

(a)

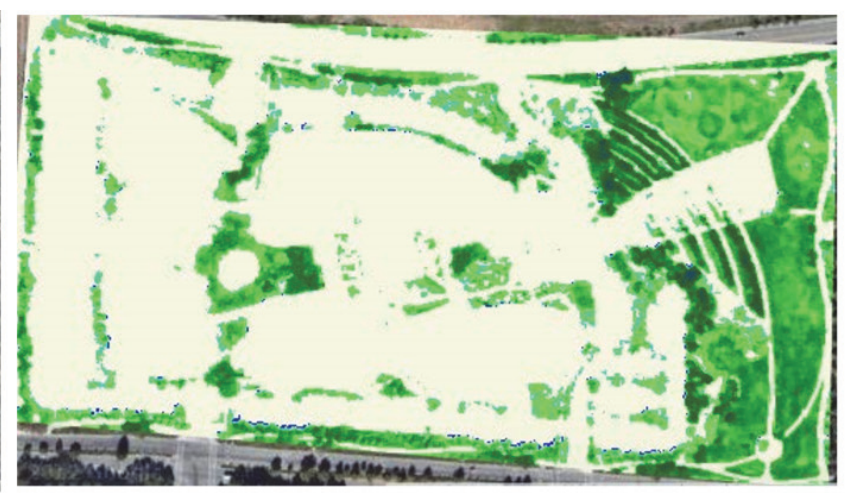

(b)

Figure 4. (a) Aerial photograph of Googleplex building suite in Mountain View, California, and (b) a map of estimated $K_{L}$ determined by the GEARUP application from calibrated NAIP imagery.

\section{COMPARISON OF DECOUPLED $K_{L}$ TO EXPERIMENTAL DATA}

The following comparisons provide examples of using equations 2 and 3 to reproduce measurements of $K_{L}$ from landscape experiments. Values for $K_{v}$ are taken from table 1, and $K_{d}$ and $K_{m c}$ are set to 1.0, representing full cover conditions and an assumed neutral microclimate. The stress coefficient $\left(K_{s m}\right)$ of equation 2 is set to a value that approximately reproduces the measured $K_{L}=0.90$. As a first example, Brown et al. (2001) reported $K_{L}$ for Tiffany bermudagrass, a warm-season grass, in Tucson, Arizona, with daily to threeday watering ranging from 0.78 during high $\mathrm{ET}_{o}$ periods (June and July) to 0.83 during low $\mathrm{ET}_{o}$ periods (September). Using $K_{v}=0.90$ for warm-season grass from table $1, K_{d}=1$, $K_{m c}=1$, and mild stress so that $K_{s m}=0.90$, the estimated $K_{L}$ from equation 2 is $K_{v} K_{d} K_{s m} K_{m c} \approx 0.80$, which reproduces the experimental data. Using equation 21 or table 6 to add effects of evaporation from soil, the $K_{L}$ associated with these values for a three-day wetting frequency is 0.84 during high $\mathrm{ET}_{o}$ periods $\left(\mathrm{ET}_{o}=8 \mathrm{~mm} \mathrm{~d}^{-1}\right)$ and 0.88 during low $\mathrm{ET}_{o}$ periods $\left(\mathrm{ET}_{o}=4 \mathrm{~mm} \mathrm{~d}^{-1}\right)$. These values are about $10 \%$ greater than reported by Brown et al. (2001). The twice-weekly mowing height reported by Brown et al. (2001) was 22 to 25 $\mathrm{mm}$, which is relatively short and may explain the differences between the $K_{L}$ estimated by equation 21 and the reported $K_{L}$. If no water stress is assumed by Brown et al. (2001), then $K_{s m}=1.0$ and $K_{L o}=K_{v} K_{d} K_{s m} K_{m c} \approx 0.9$, and from equation 24 or table 7 (interpolated) for daily watering, $K_{L}=$ 0.96 under $\mathrm{ET}_{o}=4 \mathrm{~mm} \mathrm{~d}^{-1}$ and $K_{L}=0.93$ under $\mathrm{ET}_{o}=8 \mathrm{~mm}$ $\mathrm{d}^{-1}$. These values are about $15 \%$ greater than reported by Brown et al. (2001) and may be due to the short and frequent cutting heights in their study. Brown et al. (2001) reported $K_{L}$ values for bermudagrass from the literature ranging from 0.57 to 0.83 . Those values include some amount of managed water stress.

Brown et al. (2001) reported $K_{L}$ for Froghair intermediate ryegrass, a cool-season grass, over-seeded into bermudagrass in Tucson, Arizona, ranging from 0.85 to 0.90 during high $\mathrm{ET}_{o}$ periods (May and June) and from 0.78 to 0.82 during low $\mathrm{ET}_{o}$ periods with short day lengths (December to February). Those values can be approximately reproduced using $K_{v}=0.90$ for cool-season grass from table $1, K_{d}=1.00$, $K_{m c}=1.00$, and mild stress $K_{s m}=0.90$, and a three-day watering interval. The resulting $K_{L}$ estimated from equation 21 or table 6 during high $\mathrm{ET}_{o}$ periods is $\sim 0.84$ when $\mathrm{ET}_{o}=8$ $\mathrm{mm} \mathrm{d}^{-1}$ and 0.88 in low $\mathrm{ET}_{o}$ periods when $\mathrm{ET}_{o}=4 \mathrm{~mm} \mathrm{~d}^{-1}$. These values are about 5\% lower than reported by Brown et al. (2001) for the high $\mathrm{ET}_{o}$ periods and about $10 \%$ greater than reported by Brown et al. (2001) for the low $\mathrm{ET}_{o}$ periods. Brown et al. (2001) reported $K_{L}$ values for cool-season turf grasses from the literature ranging from 0.60 to 1.04 .

Figures 5 and 6 compare monthly $K_{L}$ for warm-season grasses and cool-season grasses derived using equation 3 and tables 1 to 3 with measurements by eddy covariance from Florida (Jia et al., 2007) and by time domain reflectometry measurements of soil water in Georgia (Carrow, 1995). The $K_{L}$ values reported for the warm-season bahiagrass measured by Jia et al. (2007) include some water-stressed time periods, as do those measured by Carrow (1995), where both wet and stressed periods are included in the two-year data sets. Equation 3 with $K_{v}=0.90$ for both warm-season and cool-season grasses from table 1 for the growing season and with $K_{d}$ $=1.00, K_{m c}=1.00$, and $K_{s m}=0.80$ for warm-season and $K_{s m}$ $=0.90$ for cool-season curves produces $K_{L}$ of 0.72 for warmseason grass and 0.81 for cool-season grass. $K_{s m}=0.80$ and $K_{s m}=0.90$ are recommended for low amounts of stress, on average, for the two grass types. A value of $K_{\text {soil }}=0.20$ was used during the offseason, with $K_{d}=0.0$, to reflect background evaporation from dormant turf. It was assumed that no over-seeding of cool-season grass occurred during winter.

Estimated $K_{L}$ compares favorably with measured $K_{L}$, which includes periods of both stress and no stress. The $K_{L}$ curve measured for bahiagrass in central Florida is greater than the straight-line target curve during April and May, when the climate was generally wet, and then steadily follows the target curve during June to September, when some stress occurred due to longer times between wetting events (Jia et al., 2007). The data from Carrow (1995) fall below the target curve during June to August, when substantial stress occurred, and rise above the target curve during the wetter period of September. The trends observed by Carrow (1995) for cool-season tall fescue grasses are similar for the same reasons. On average, the observed data follow the steady target $K_{L}$ values within the uncertainties common to water measurement, management, and variation in weather. 


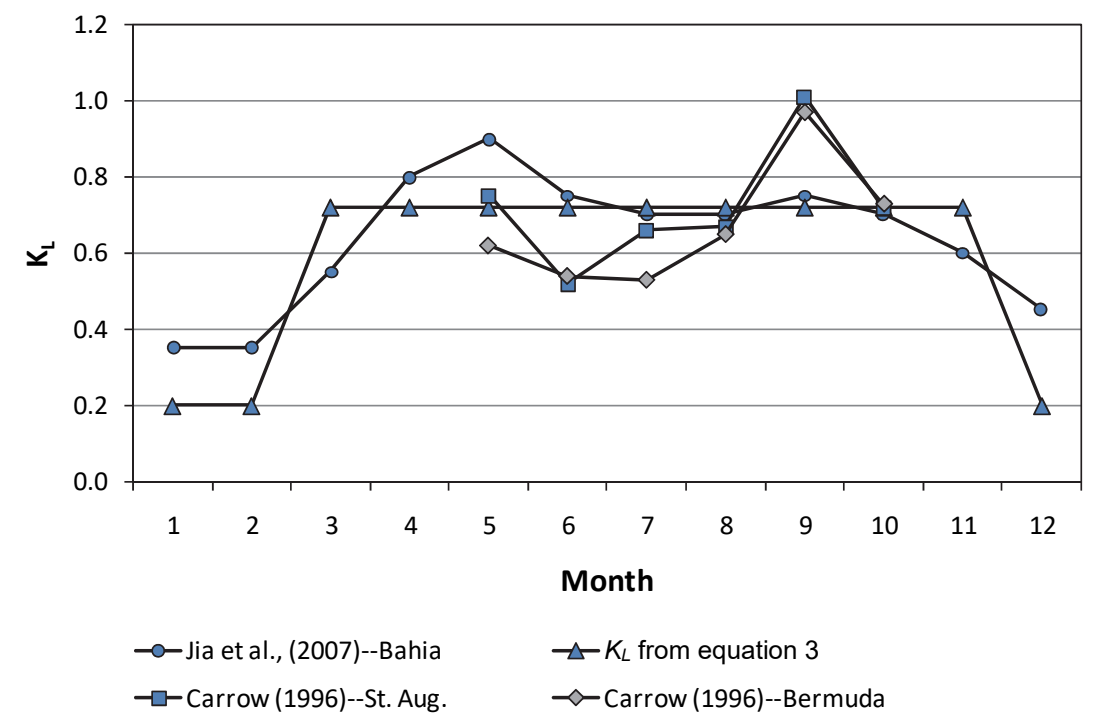

Figure 5. Measured monthly $K_{L}$ for bahiagrass in Florida reported by Jia et al. (2009) and for St. Augustine and bermuda grasses in Georgia reported by Carrow (1996) compared with a steady target $K_{L}$ from equation 3 and tables 1 to 3 for a warm-season grass (data are from Jia et al., 2009, and Carrow, 1995, 1996).

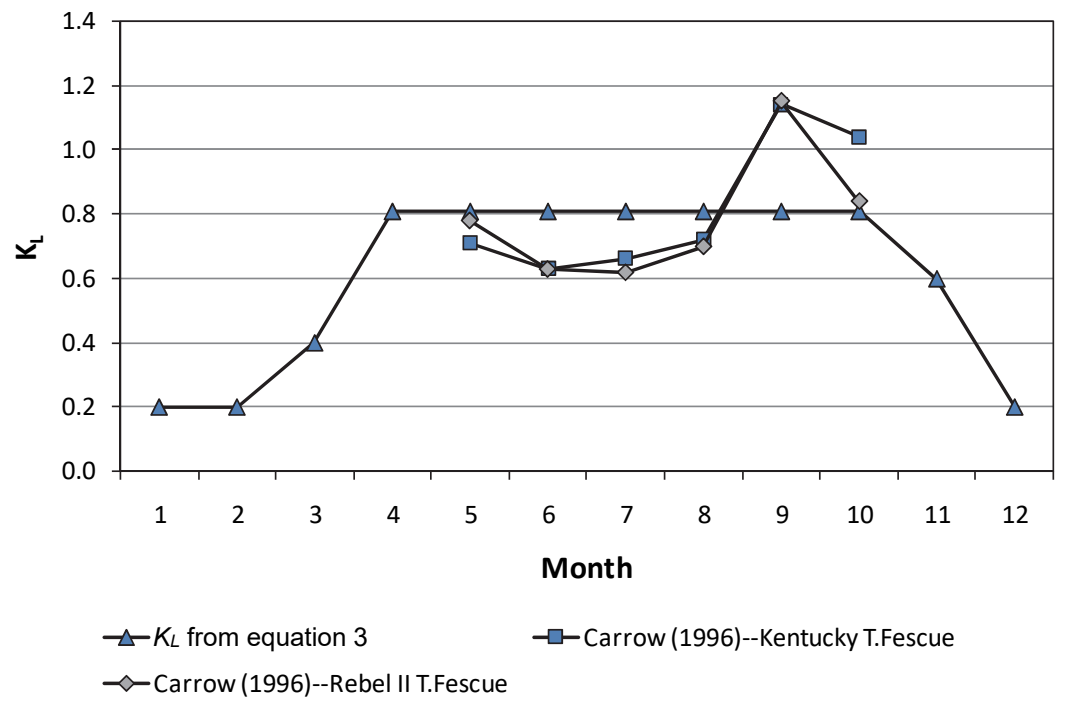

Figure 6. Measured monthly $K_{L}$ for two types of tall fescue grass in Georgia reported by Carrow (1996) compared with a steady target $K_{L}$ from equation 3 and tables 1 to 3 for a cool-season grass (data are from Carrow, 1995, 1996).

\section{CONCLUSIONS}

The multi-component decoupling method, $K_{L}=$ $K_{v} K_{d} K_{s m} K_{m c}$, for the landscape coefficient accounts for variations in vegetation type, density, local climate, and soil water management. The method can help to accomplish objectives for water management of landscapes that are increasingly targeted toward water conservation while maintaining general vegetation greenness and health. The multi-component method is somewhat complicated in order to estimate water requirements of landscapes that can be highly variable. However, the methodology can be programmed into software applications in which the component coefficients are selected from tables or are computed from other parameters. The upper bounds of 1.00 for modifying coefficients $K_{d}, K_{m c}$, and $K_{s m}$ simplify their estimation and reduce uncertainties.
Each coefficient can be estimated using readily observable descriptions of a landscaped area, coupled with management objectives. The incorporation of evaporation from soil and intercepted water on foliage in equations 3 and 21 provide an opportunity to assess the effects of wetting frequency on total water consumption. The effects of soil wetting diminish as vegetation density increases, and the relative effects of interception from frequent irrigation decrease as the reference ET rate increases.

Target $K_{L}$ estimates are useful for planning and recommending guidelines for water conservation programs. Actual $K_{L}$ estimates are useful for assessing results of water management practices and for use in hydrologically based water balances. The procedure in ASABE Standard S623 for estimating recommended target water requirements represents a 
simplified and reduced form of the multi-component IA procedure and is complementary to that procedure.

\section{ACKNOWLEDGEMENTS}

Substantial first efforts at formulating a multi-component procedure were conducted by the WUCOLS program of California. Those efforts pointed the way to evolving the Irrigation Association method described here. The authors acknowledge funding support from the Idaho Agricultural Experiment Station, University of Florida Institute of Agricultural Sciences, Utah Agricultural Experiment Station, University of California Cooperative Extension, and Nebraska Agricultural Experiment Station and guidance support from the Irrigation Association, ASABE, and ASCE. Valuable recommendations by the anonymous reviewers are also acknowledged and appreciated.

\section{REFERENCES}

Allen, R. G., \& Pereira, L. S. (2009). Estimating crop coefficients from fraction of ground cover and height. Irrig. Sci., 28(1), 1734. https://doi.org/10.1007/s00271-009-0182-z

Allen, R. G., Howell, T. A., \& Snyder, R. L. (2011). Irrigation water requirements. In L. E. Stetson \& B. Q. Mecham (Eds.), Irrigation (6th Ed., pp. 93-172). Falls Church, VA: Irrigation Association.

Allen, R. G., Pereira, L. S., Raes, D., \& Smith, M. (1998). Crop evapotranspiration: Guidelines for computing crop water requirements. Irrigation and Drainage Paper No. 56. Rome, Italy: United Nations FAO.

Allen, R. G., Pereira, L. S., Smith, M., Raes, D., \& Wright, J. L. (2005). FAO-56 dual crop coefficient method for estimating evaporation from soil and application extensions. J. Irrig. Drain. Eng., 131(1), 2-13. https://doi.org/10.1061/(ASCE)07339437(2005)131:1(2)

Allen, R. G., Prueger, J. H., \& Hill, R. W. (1992). Evapotranspiration from isolated stands of hydrophytes: Cattail and bulrush. Trans. ASAE, 35(4), 1191-1198. https://doi.org/10.13031/2013.28719

Allen, R. G., Pruitt, W. O., \& Jensen, M. E. (1991). Environmental requirements of lysimeters. In R. G. Allen, T. A. Howell, W. O. Pruitt, I. A. Walter, \& M. E. Jensen (Eds.), Lysimeters for evapotranspiration and environmental measurements (Vols. 170-181.3). New York, NY: ASCE.

Allen, R. G., Pruitt, W. O., Wright, J. L., Howell, T. A., Ventura, F., Snyder, R., ... Smith, M. (2006). A recommendation on standardized surface resistance for hourly calculation of reference $\mathrm{ET}_{\mathrm{o}}$ by the FAO56 Penman-Monteith method. Agric. Water Mgmt., 81(1-2), 1-22. https://doi.org/10.1016/j.agwat.2005.03.007

Aronson, L. J., Gold, A. J., \& Hull, R. J. (1987). Cool-season turfgrass responses to drought stress. Crop Sci., 27(6), 12611266. https://doi.org/10.2135/cropsci1987.0011183X002700060035x

ASABE. (2017). S623.1: Determining landscape plant water demands. St. Joseph, MI: ASABE.

ASCE. (2005). The ASCE standardized reference evapotranspiration equation. Task committee on standardized calculation of reference evapotranspiration calculation. Reston, VA: ASCE.

ASCE. (2016). Evaporation, evapotranspiration and irrigation water requirements (2nd Ed.). ASCE Manual of Practice No. 70. Reston, VA: ASCE.
Breuer, L., Eckhardt, K., \& Frede, H.-G. (2003). Plant parameter values for models in temperate climates. Ecol. Model., 169(2), 237-293. https://doi.org/10.1016/S0304-3800(03)00274-6

Brown, P. W., Mancino, C. F., Young, M. H., Thompson, T. L., Wierenga, P. J., \& Kopec, D. M. (2001). Penman-Monteith crop coefficients for use with desert turf systems. Crop Sci., 41(4), 1197-1206. https://doi.org/10.2135/cropsci2001.4141197x

Brutsaert, W. (1982). Evaporation into the atmosphere. Dordrecht, The Netherlands: D. Reidel. https://doi.org/10.1007/978-94-0171497-6

Burt, C. M., Mutziger, A. J., Howes, D. J., \& Solomon, K. H. (2005). Evaporation from irrigated agricultural land in California. Report No. 02-001. San Luis Obispo, CA: Cal Poly Irrigation Training and Research Center.

Carlson, T. N., \& Ripley, D. A. (1997). On the relation between NDVI, fractional vegetation cover, and leaf area index. Remote Sensing Environ., 62(3), 241-252. https://doi.org/10.1016/S0034-4257(97)00104-1

Carrow, R. N. (1995). Drought resistance aspects of turfgrasses in the southeast: Evapotranspiration and crop coefficients. Crop Sci., 35(6), 1685-1690. https://doi.org/10.2135/cropsci1995.0011183X003500060029x

Carrow, R. N. (1996). Drought resistance aspects of turfgrasses in the southeast: Root-shoot responses. Crop Sci., 36(3), 687-694. https://doi.org/10.2135/cropsci1996.0011183X003600030028x

Carrow, R. N. (2004). Can we maintain turf to customers' satisfaction with less water? Proc. 4th Intl. Crop Science Congress. Retrieved from www.cropscience.org.au

Cesaraccio, C., Spano, D., Duce, P., \& Snyder, R. L. (2001). An improved model for determining degree-day values from daily temperature data. Intl. J. Biometeorol., 45(4), 161-169. https://doi.org/10.1007/s004840100104

Choudhury, B. J., \& Monteith, J. L. (1986). Implications of stomatal response to saturation deficit for the heat balance of vegetation. Agric. Forest Meteorol., 36(3), 215-225. https://doi.org/10.1016/0168-1923(86)90036-5

Costello, L. R., \& Jones, K. S. (1999). A guide to estimating irrigation water needs of landscape plantings in California: Part 2. WUCOLS III. Berkeley, CA: University of California Extension.

Costello, L. R., \& Jones, K. S. (2014). Water use classification of landscape species: WUCOLS IV. Berkeley, CA: University of California Extension.

Costello, L. R., Matheny, N. P., \& Clark, J. R. (2000). A guide to estimating irrigation water needs of landscape plantings in California: Part 1: The landscape coefficient method. Berkeley, CA: University of California Extension.

Davis, S. L., \& Dukes, M. D. (2010). Irrigation scheduling performance by evapotranspiration-based controllers. Agric. Water Mgmt., 98(1), 19-28. https://doi.org/10.1016/j.agwat.2010.07.006

Doorenbos, J., \& Kassam, A. H. (1979). Yield response to water. FAO Irrigigation and Drainage Paper No. 33. Rome, Italy: United Nations FAO.

Doorenbos, J., \& Pruitt, W. O. (1977). Guidelines for predicting crop water requirements. FAO Irrigation and Drainage Paper No. 24. Rome, Italy: United Nations FAO.

Fereres, E. (1981). Drip irrigation management. Leaflet No. 21259. Berkeley, CA: University of California Cooperative Extension.

Gilman, E. F. (1990a). Tree root growth and development: I. Form, spread, depth, and periodicity. J. Environ. Hortic., 8(4), 215 220.

Gilman, E. F. (1990b). Tree root growth and development: II. Response to culture, management, and planting. J. Environ. Hortic., 8(4), 220-227. 
Glenn, E. P., Nagler, P. L., \& Huete, A. R. (2010). Vegetation index methods for estimating evapotranspiration by remote sensing. Surv. Geophys., 31(6), 531-555. https://doi.org/10.1007/s10712010-9102-2

Goldberg, V., \& Bernhofer, C. (2008). Testing different decoupling coefficients with measurements and models of contrasting canopies and soil water conditions. Ann. Geophys., 26(7), 19771992. https://doi.org/10.5194/angeo-26-1977-2008

Greenly, K. M., \& Rakow, D. A. (1995). The effect of wood mulch type and depth on weed and tree growth and certain soil parameters. J. Arboriculture, 21, 225-225.

Harivandi, M. A., Baird, J., Hartin, J., Henry, M., \& Shaw, D. (2009). Managing turfgrasses during drought. UCANR Publication 8395. Oakland, CA: University of California Division of Agriculture and Natural Resources. https://doi.org/10.3733/ucanr.8395

Hernandez-Suarez, M. (1988). Modeling irrigation scheduling and its components and optimization of water delivery scheduling with dynamic programming and stochastic $\mathrm{ET}_{o}$ data. $\mathrm{PhD}$ diss. Davis, CA: University of California.

Hoffman, F. O., Thiessen, K. M., Frank, M. L., \& Blaylock, G. B. (1992). Quantification of the interception and initial retention of radioactive contaminants deposited on pasture grass by simulated rain. Atmos. Environ., 26(18), 3313-3321. https://doi.org/10.1016/0960-1686(92)90348-O

Hunsaker, D. J., French, A. N., Clarke, T. R., \& El-Shikha, D. M. (2011). Water use, crop coefficients, and irrigation management criteria for camelina production in arid regions. Irrig. Sci., 29(1), 27-43. https://doi.org/10.1007/s00271-010-0213-9

IA. (2003). Landscape irrigation scheduling and water management: Practices guidelines. Falls Church, VA: Irrigation Association. Retrieved from http://www.irrigation.org/uploadedFiles/Resources/BMP_Revise d_12-2010.pdflast

IA. (2011). Irrigation (6th Ed.). Falls Church, VA: Irrigation Association.

Jarvis, P. G., \& McNaughton, K. G. (1986). Stomatal control of transpiration: Scaling up from leaf to region. In A. MacFadyen \& E. D. Ford (Eds.), Advances in ecological research (Vol. 15, pp. 1-49). Cambridge, MA: Academic Press. https://doi.org/10.1016/S0065-2504(08)60119-1

Jensen, M. E. (1968). Water consumption by agricultural plants. In T. T. Kozlowski (Ed.), Water deficits and plant growth (Vol. II, pp. 1-22). New York, NY: Academic Press.

Jensen, M. E. (1969). Scheduling irrigation with computers. J. Soil Water Cons., 24(5), 193-195.

Jensen, M. E., Robb, D. C. N., \& Franzoy, C. E. (1970). Scheduling irrigations using climate-crop-soil data. J. Irrig. Drain. Div., 96(IRI), 25-38.

Jensen, M. E., Wright, J. L., \& Pratt, B. J. (1971). Estimating soil moisture depletion from climate, crop, and soil data. Trans. ASAE, 14(5), 954-959. https://doi.org/10.13031/2013.38430

Jia, X., Dukes, M. D., \& Jacobs, J. M. (2007). Development of bahiagrass crop coefficient in a humid climate. ASABE Paper No. 072151. St. Joseph, MI: ASABE.

Jia, X., Dukes, M. D., \& Jacobs, J. M. (2009). Bahiagrass crop coefficients from eddy correlation measurements in central Florida. Irrig. Sci., 28(1), 5-15. https://doi.org/10.1007/s00271009-0176-X

Jordan, J. E., White, R. H., Vietor, D. M., Hale, T. C., Thomas, J. C., \& Engelke, M. C. (2003). Effect of irrigation frequency on turf quality, shoot density, and root length density of five bentgrass cultivars. Crop Sci., 43(1), 282-287. https://doi.org/10.2135/cropsci2003.2820

Kilic, A., Ozturk, D., Ortega, S., Kamble, B., Ratcliffe, I., Allen, R. G., ... Moore, R. (2017). G.E.A.R.U.P. - Google Earth engine app for residential water use and preservation. Presentation to the USGS Landsat Science Team.

Kjelgren, R., \& Montague, T. (1998). Urban tree transpiration over turf and asphalt surfaces. Atmos. Environ., 32(1), 35-41. https://doi.org/10.1016/S1352-2310(97)00177-5

Kjelgren, R., Beeson Jr., R. C., Pittenger, D. P., \& Montague, T. (2016). Simplified landscape irrigation demand estimation: SLIDE rules. Appl. Eng. Agric., 32(4), 363-378. https://doi.org/10.13031/aea.32.11307

Kjelgren, R., Rupp, L., \& Kilgren, D. (2000). Water conservation in urban landscapes. HortSci., 35(6), 1037-1040. https://doi.org/10.21273/hortsci.35.6.1037

Kluge, M., \& Ting, I. P. (2012). Crassulacean acid metabolism: Analysis of an ecological adaptation. Berlin, Germany: Springer.

Lee, S.-K. (2014). Irrigation frequency and nitrogen rates for tall fescue growth. Weed Turfgrass Sci., 3(2), 130-136. https://doi.org/10.5660/WTS.2014.3.2.130

Martin, D. L., \& Gilley, J. (1993). Irrigation water requirements. In National engineering handbook (Chapter 2, Part 623). Bethesda, MD: USDA Soil Conservation Service.

McDonald, D. K. (1999). Ecologically sound lawn care for the Pacific Northwest: Findings from the scientific literature and recommendations from turf professionals. Seattle, WA: Seattle Public Utilities, Resource Conservation Section.

Meyer, J., \& Gibeault, V. A. (1986). Turfgrass performance under reduced irrigation. California Agric., 40(7), 19-20.

Neale, C. M., Jayanthi, H., \& Wright, J. L. (2005). Irrigation water management using high-resolution airborne remote sensing. Irrig. Drain. Syst., 19(3), 321-336. https://doi.org/10.1007/s10795-005-5195-z

Pittenger, D. R., \& Henry, J. M. (2005). Refinement of urban landscape water requirements. Irvine, CA: University of California Cooperative Extension, South and Central Coast and South Region.

Pittenger, D. R., \& Shaw, D. (2001). Applications of recent research in landscape irrigation management. Proc. UCR Turfgrass and Landscape Management Field Day (pp. 17-18). Riverside, CA: University of California.

Pittenger, D., \& Shaw, D. (2004). What we know about landscape water requirements. CO-Hort, 6.1, 1-4.

Pittenger, D., \& Shaw, D. A. (2007). Review of research on water needs of landscape plants. Proc. Symp. on Efficient Water Use in the Urban Landscape. Las Cruces, NM: New Mexico State University.

Qi, M. Q., \& Redmann, R. E. (1993). Seed germination and seedling survival of $\mathrm{C} 3$ and $\mathrm{C} 4$ grasses under water stress. $J$. Arid. Environ., 24(3), 277-285. https://doi.org/10.1006/jare.1993.1024

Qian, Y. L., \& Fry, J. D. (1996). Irrigation frequency affects zoysiagrass rooting and plant water status. HortSci., 31(2), 234237. https://doi.org/10.21273/hortsci.31.2.234

Raes, D., Steduto, P., Hsiao, T. C., \& Fereres, E. (2009). AquaCrop: The FAO crop model to simulate yield response to water: II. Main algorithms and software description. Agron. J., 101(3), 438-447. https://doi.org/10.2134/agronj2008.0140s

Reid, K., \& Oki, L. R. (2016). Evaluation of ornamental plant performance on four deficit irrigation levels: Working with industry to promote sustainable plant choices for summer-dry regions. Acta Hort., 1112, 155-162. https://doi.org/10.17660/ActaHortic.2016.1112.22

Reid, K., Fujino, D., Oki, L. R., Hartin, J., Ingels, C., Haver, D., ... Duenow, B. (2018). Maintaining urban landscape health and services on reduced irrigation: A multi-site study in best management practices. Acta Hort., 1215(175-180). https://doi.org/10.17660/ActaHortic.2018.1215.33 
Reid, S. K., \& Oki, L. R. (2008). Field trials identify more native plants suited to urban landscaping. California Agric., 62(3), $97-$ 104. https://doi.org/10.3733/ca.v062n03p97

Richie, W. E., \& Pittenger, D. R. (2000). Mixed landscape irrigation research findings. Proc. UCR Turfgrass and Landscape Management Research Conf. (pp. 12-13). Riverside, CA: University of California.

Richie, W. E., Green, R. L., Klein, G. J., \& Hartin, J. S. (2002). Tall fescue performance influenced by irrigation scheduling, cultivar, and mowing height. Crop Sci., 42(6), 2011-2017. https://doi.org/10.2135/cropsci2002.2011

Ritchie, J. T., \& Nesmith, D. S. (1991). Temperature and crop development. In Modeling plant and soil systems (pp. 5-29). Agronomy Monograph No. 31. Madison, WI: ASA, CSSA, SSSA. https://doi.org/10.2134/agronmonogr31.c2

Romero, C. C., \& Dukes, M. D. (2016). Review of turfgrass evapotranspiration and crop coefficients. Trans. ASABE, 59(1), 207-223. https://doi.org/10.13031/trans.59.11180

Slack, D. C., Martin, E. C., Sheta, A. E., Fox Jr, F., Clark, L. J., \& Ashley, R. O. (1996). Crop coefficients normalized for climatic variability with growing-degree-days. Proc. Intl. Conf. on Evapotranspiration and Irrigation Scheduling (pp. 3-6). St. Joseph, MI: ASABE.

Smeal, D., O’Neill, M. K., \& Arnold, R. N. (2005). Forage production of cool-season pasture grasses as related to irrigation. Agric. Water Mgmt., 76(3), 224-236. https://doi.org/10.1016/j.agwat.2005.01.014

Smeal, D., Owen, C. K., Arnold, R. N., Tomko, J. F., \& Gregory, E. J. (2001). Thirty years of climatological data, 1969 to 1998. Research Report 744. Las Cruces, NM: New Mexico State University Agricultural Experiment Station.

Snyder, R. L. (1985). Hand calculating degree days. Agric. Forest Meteorol., 35(1), 353-358. https://doi.org/10.1016/01681923(85)90095-4

Snyder, R. L., \& Eching, S. O. (2004). Landscape irrigation management program: IS005 Quick Answers. Davis, CA: University of California.

Snyder, R. L., \& Eching, S. O. (2005). Urban landscape evapotranspiration. In California Water Plan Update 2005 (Vol. 4, pp. 691-693.
Snyder, R. L., Pedras, C., Montazar, A., Henry, J. M., \& Ackley, D. (2015). Advances in ET-based landscape irrigation management. Agric. Water Mgmt., 147, 187-197. https://doi.org/10.1016/j.agwat.2014.07.024

Snyder, R. L., Spano, D., Cesaraccio, C., \& Duce, P. (1999). Determining degree-day thresholds from field observations. Intl. J. Biometeorol., 42(4), 177-182. https://doi.org/10.1007/s004840050102

St. Hilaire, R., Arnold, M. A., Wilkerson, D. C., Devitt, D. A., Hurd, B. H., Lesikar, B. J., ... Zoldoske, D. F. (2008). Efficient water use in residential urban landscapes. HortSci., 43(7), 20812092. https://doi.org/10.21273/hortsci.43.7.2081

Tucker, C. J. (1979). Red and photographic infrared linear combinations for monitoring vegetation. Remote Sensing Environ., 8(2), 127-150. https://doi.org/10.1016/00344257(79)90013-0

UCANR. (2020). Using ANSI/ASABE S623 and SLIDE to estimate landscape water requirements. Riverside, CA: University of California Division of Agricultur and Natural Resources. Retrieved from https://ucanr.edu/sites/UrbanHort/Water_Use_of_Turfgrass_and _Landscape_Plant_Materials/SLIDE_Simplified_Irrigation_De mand_Estimation/

van Bavel, C. H. M., Fritschen, L. J., \& Reeves, W. E. (1963). Transpiration by sudangrass as an externally controlled process. Science, 141(3577), 269-270. https://doi.org/10.1126/science.141.3577.269-a

Way, D. A., Katul, G. G., Manzoni, S., \& Vico, G. (2014). Increasing water use efficiency along the $\mathrm{C} 3$ to $\mathrm{C} 4$ evolutionary pathway: A stomatal optimization perspective. J. Exp. Bot., 65(13), 3683-3693. https://doi.org/10.1093/jxb/eru205

Wright, J. L. (1982). New evapotranspiration crop coefficients. $J$. Irrig. Drain. Div., 108(2), 57-74.

Wright, J. L. (1993). Nongrowing season ET from irrigated fields: Management of irrigation and drainage systems. Proc. ASCE Spec. Conf. (pp. 1005-1014). Reston, VA: ASCE.

Zinke, P. J. (1967). Forest interception studies in the United States. In W. E. Sopper \& H. W. Lull (Eds.), Forest hydrology (pp. 137-161). Oxford, UK: Pergamon. 